\title{
Assessment of IEC Normal Turbulence Model and Modelling of the Wind Turbulence Intensity for Small Wind Turbine Design in Tropical Area: Case of the Coastal Region of Benin
}

\author{
Hagninou Elagnon Venance Donnou ${ }^{a^{*}}$, Aristide Barthélémy Akpo ${ }^{a}$, Guy Hervé \\ Hounguèa,b, Basile Bruno Kounouhewa ${ }^{a, b}$
}

\author{
${ }^{a}$ Laboratoire de Physique du Rayonnement (LPR), Faculté des Sciences et Techniques (FAST), Université d'Abomey-Calavi, 01 B.P.526, \\ Cotonou, Benin \\ ${ }^{b}$ Centre Béninois de la Recherche Scientifique et de l'Innovation, Cotonou, Bénin
}

\begin{abstract}
The wind turbulence intensity observed on a site have an influence the wind turbine energy production and the lifetime of the blades. It is therefore primordial to master this parameter for the optimization of the production. So therefore, this study is interested on the modelling of the wind turbulence intensity at $10 \mathrm{~m}$ above the ground on the coast of Benin. Four years of wind data measured on the site of Cotonou Port Authority (PAC) from 2011 to 2014 and recorded with a temporal resolution of 10 min were used. From the transport equation of turbulent kinetic energy followed by a numerical simulation based on the Nelder-Mead algorithm developed under the Matlab software, we proposed five new models for estimating the wind turbulence intensity. The results of the different simulations reveal that four of proposed models and based on the roughness, the speed of friction and the length of Obukhov better fit the data, during the periods of January, April, June, July, August, September and December. The estimators of the Root Mean Square Error (RMSE) and the Mean Absolute Error (MAE) vary from $(0.02 ; 0.01)$ in December to $(0.09 ; 0.07)$ in August. As for the model which is a function of roughness and the wind shear coefficient (expressed only according to the wind speed), it gives better performance whatever the time of the year and the atmosphere stability conditions. The estimations errors are included between (0.02; 0.01) obtained in December and $(0.08 ; 0.06)$ observed in March. A comparative study between the existing models in the literature and the best model proposed in this study showed that only this model gives the best adjustment with the data. It can therefore be used on the sites where turbulence is influenced by the roughness and the atmosphere stability. Finally, from this model a new wind turbine design class has been proposed for the site of Cotonou. It takes into account the actual levels of turbulence observed and thus allow to optimize the energy production. (C2020. CBIORE-IJRED. All rights reserved
\end{abstract}

Keywords: Atmosphere, Model, Simulation, Turbulence intensity, Wind speed

Article History: Received: $3^{\text {rd }}$ January 2020; Revised: $7^{\text {th }}$ April 2020 ; Accepted: $12^{\text {th }}$ April 2020; Available online: $13^{\text {th }}$ May 2020

How to Cite This Article: Donnou, H.E.V., Akpo, A.B., Houngue, G.H. and Kounouhewa, B.B. (2020) Assessment of IEC Normal Turbulence Model and Modelling of the Wind Turbulence Intensity for Small Wind Turbine Design in Tropical Area: Case of the Coastal Region of Benin. International Journal of Renewable Energy Development, 9(2), 263-286

https://doi.org/10.14710/ijred.9.2.263-286

\section{Introduction}

Wind turbulence intensity is an important parameter for the induced loads evaluation by the wind on the wind turbines components as well as for their design (Ren et al. 2018; Dimitrov et al. 2015). In the atmospheric boundary layer where wind turbines are generally installed, this phenomenon of turbulence is high (Finnigan 1994). Such complex environments (near-ground) induce a stochastic variation in wind speed and turbulence intensity difficult to estimate (Evans et al. 2017). They cause thus the angle of attack fluctuations for the blade element (Kamada et al. 2011) inducing thus the fatigue loading which reduces their lifetime (Peña et al. 2015; Cheung et al. 2016; Stival et al. 2017; Carpman 2011; Marino et al. 2017; Dimitrov et al. 2017; Kim et al. 2015). This turbulence (low frequency), measured within a period of $10 \mathrm{~min}$, affects also wind energy production (Peña et al. 2015; Cheung et al. 2016; Stival et al. 2017; Rosen and Sheinman 1994; Kaiser et al. 2004; Gottschall and Peinke 2008; Sonia and Lundquist; Siddiqui et al. 2015; Hedevang 2014). The variation of the component loads therefore depends significantly of this parameter inherent at the wind field. As a result, wind fluctuation speed models are very important for the design, the operation of wind turbines (Leu et al. 2014). For this task, IEC 61400 standard of the International Electrotechnical Commission (IEC) standards, has been designed by the European and the American countries to provide the wind turbine designer the valuable

\footnotetext{
* Corresponding author: donhelv@yahoo.fr (Tel: +229 961301 52)
} 
information. It is a set of design requirements to ensure the proper operation and life of wind turbines and recommended for the design of wind turbines. This standard considers the Normal Turbulence Model (NTM) as a reference for fatigue load calculations for wind turbines (Lopez-Villalobos et al. 2018).

However, several authors have questioned about the suitability of NTM in certain turbulent environments since it does not include the wind dynamics related to such highly turbulent sites (Lopez-Villalobos et al. 2018). This is the case of Ishihara et al. (2012) who after studying the characteristics of the turbulence with the IEC61400-1 standard model on an offshore site in Japan, noticed that this model underestimated the turbulence intensity. The authors therefore propose the determination of the suitable parameters of the model for the site in order to improve the accuracy of the estimate. Leu et al. (2014) studied the performance of the model in Taiwan and also determined the appropriate parameters of this model for this study area as a reference for future wind farms. Wang et al. (2013) after having evaluated the IEC61400-3 normal turbulence model at three sites in Asia, Europe and the United States, the authors developed a new model. It is taking into account the wind-wave interaction with the Charnock equation adjusted by empirical functions of turbulence scale for the unstable atmosphere. This model is a function of the roughness length, the Obukhov length and atmospheric boundary layer height and gives better performance in offshore according to the authors. As for the studies of Dimitrov et al. (2015), the authors have developed a simplified model for the exponent of the wind shear. Then, they combine it to the standard wind conditions prescribed in IEC 61400-1,3 in order to evaluate the fatigue loads on the different components of the turbine. Carpman (2011) have studied the turbulence intensity of small wind turbines. They conclude that the NTM underestimates turbulence intensity for complex environments for the high wind speeds. It represents turbulence only for the wind speeds lower than $10 \mathrm{~m} / \mathrm{s}$. On the two sites of Perth and Newcastle in Australia, the IEC 61400-2 underestimates the turbulence intensity for the majority of the measured wind speeds according to the studies of Evans et al. (2017). An aeroelastic model was therefore established in FAST using the IEC 61400-2 and the measure of the wind as an input in order to predict the main turbine performance parameters (Evans et al. 2017). In considering the studies of Ren et al. (2018), the authors noticed the normal turbulence model overestimates the turbulence intensity of the three wind farms studied. A new model of turbulence intensity estimation only depending of the wind speed, and based to the three-parameter (three constants) power law, has therefore been proposed on the basis of real observations. The actual data show that the proposed model by Ren et al. (2018) performs better than NTM. Lopez-Villalobos et al. (2018) have analysed the turbulence intensity for a range of wind speeds between 2 and $24 \mathrm{~m} / \mathrm{s}$. The results have shown that the IEC model underestimated the measures of turbulence intensity for 388 hours. The authors therefore concluded that the use of the NTM may lead to the fatigue loads and some structural damage at the wind turbine level.

Cheung et al. (2016) have developed a simple model for estimation the turbulence intensity by assuming a power law for the velocity profile. The authors established the relation between the turbulent fluctuations with the mean wind shear profile for the neutral stable Atmospheric Boundary Layers (ABL) based on the turbulent boundary layer theory. The models are related to the Mann model and shown to have a similar scaling. However they are simpler and based on assumptions for turbulent boundary layers rather than homogeneous turbulence.

This diversity of models thus shows the interest granted by the different authors for the improvement of wind turbulence intensity estimation models. After analyzing the studies above, we noted that the use of these models requires the knowledge of certain topographic and meteorological parameters such as the roughness, shear, friction speed, Obukhov length or boundary layer height that are specific to each site. Moreover, we noticed that no model has simultaneously taken into account the roughness length, shear coefficient and Obukhov length nor the roughness length and shear coefficient or shear coefficient and Obukhov length. In view of these observations, one of the best solutions which will be the subject of this study is to establish a model specific to each site considered or to similar characteristic sites based on the data. This would therefore better represent the distribution of the wind turbulence intensity. Failure to taking into account the actual levels of turbulence intensity would lead to poor prediction of the wind turbines output power, the fatigue loads and possible premature failure of the turbine components.

Our study area which is appropriate for wind energy exploitation according to the works of Awanou et al. (1991), Houekpoheha et al. (2014), Akpo et al. (2015) as well as West Africa are subject to the high wind fluctuations (Madougou 2010; Houngninou et al. 2017), due to weather conditions. Moreover, no study on the modelling of the wind turbulence intensity in this Africa area has been carried out near the ground. The aim of this study is therefore to develop a model that can suitably reproduce the turbulence intensity on our study site (Benin coast in Cotonou). Firstly, the Normal Turbulence Model (NTM) of IEC standard have been evaluated with the actual data. From the transport equation of turbulent kinetic energy, we therefore modelled the intensity of wind turbulence by an analytical approach. Then, we made an assumption that the wind average shear profile contained in the transport equation can be expressed like a function of the wind shear coefficient. The roughness length has been introduced in the equation like an increasing linear function of turbulence intensity. A numerical simulation based on the Nelder-Mead algorithm was performed to determine the model's fitting constants. Finally we proposed a new class of wind turbine design on our study site.

\section{Materials and Methods}

\subsection{Site Description and Dataset}

\subsubsection{Study area description}

The coastal region of Benin is a coastal band, low and sandy, $125 \mathrm{~km}$ long and extending from Hillacondji in the West to Kraké in the East. Table 1 presents the geographical characteristic of the coastal region of Cotonou. 
Table 1

Detailed information about the coastal region of Cotonou.

\begin{tabular}{ll}
\hline Parameters & Values \\
\hline Location & Cotonou, Benin \\
Period of record & $2011-2014$ \\
Longitude & $2^{\circ} 25^{\prime} 05^{\prime \prime} \mathrm{E}$ \\
Latitude & $6^{\circ} 21^{\prime} 55^{\prime \prime} \mathrm{N}$ \\
Height above mean sea level $(\mathrm{m})$ & 7 \\
\hline
\end{tabular}

Figure 1 presents the geographical situation of the study area.

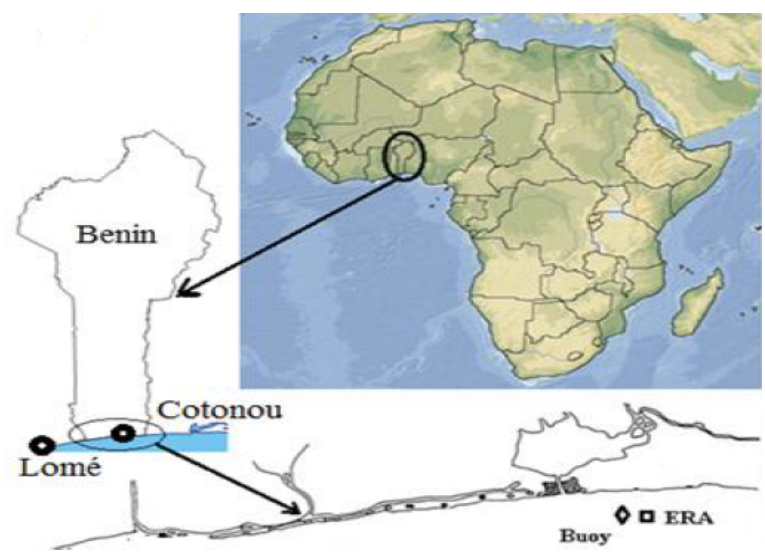

Fig. 1 Geographical location of the coast of Cotonou in Benin in Gulf of Guinea (Hounguè et al. 2018)

\subsubsection{Dataset}

During the Millennium Challenge Account compact I (MCA), the wind data have been recorded (speed and direction) at $10 \mathrm{~m}$ above the ground for the period from June 1st, 2011 to April 30th, 2014. Table 2 gives the description of wind sensor which was used during the measure. Fig. 2 shows an overview of the wind observation system on the port platform located on the Cotonou coast.

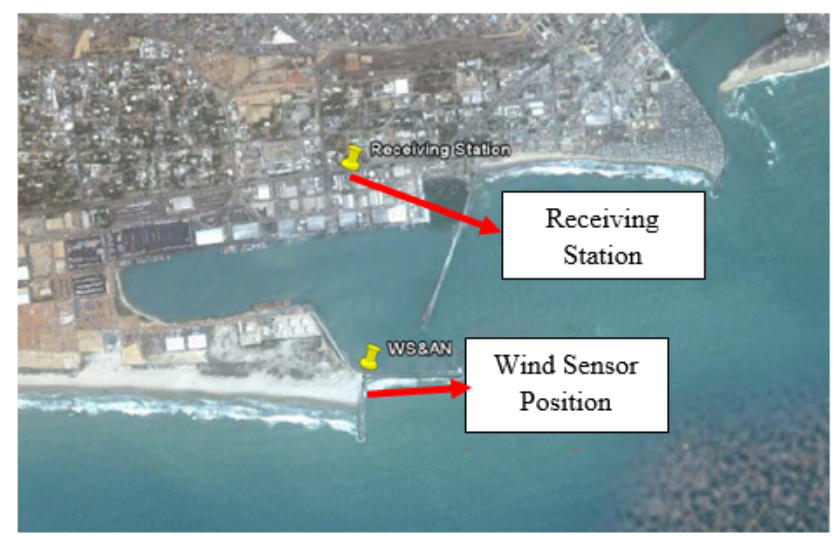

Fig. 2 Wind sensor with the data logger position (receiving station) in the seaside (Richard and Dolle 2011)

\subsection{Theory}

\subsubsection{Turbulence Intensity}

In wind resource analysis, turbulence is measured by turbulence intensity. It is defined as the ratio between standard deviation and the horizontal wind speed over a 10 minutes period (Barthelmie et al. 2007; Mirhosseini et al. 2011).

$I=\frac{\sigma}{U}$

$\sigma$ is the standard deviation of the horizontal wind speed $(\mathrm{m} / \mathrm{s})$ and $U$ is the average horizontal wind speed $(\mathrm{m} / \mathrm{s})$.

Table 2

Description of the observation system.

\begin{tabular}{ccc}
\hline & $\begin{array}{c}\text { Manufacturer } \\
\text { Type }\end{array}$ & $\begin{array}{c}\text { WXT520 VAISALA } \\
\text { S/N 61830010 } \\
\text { Cup-vane } \\
\text { anemometer }\end{array}$ \\
& & $\begin{array}{c}\text { Detection method } \\
\text { Wind direction }\end{array}$ \\
Logger & Observed data & $\begin{array}{c}\text { Averaged over } 2 \text { and } \\
10 \text { minutes every } 10\end{array}$ \\
& & minutes \\
Wind sensor & Latitude & $6^{\circ} 20^{\prime} 554^{\prime \prime} \mathrm{N}$ \\
localization & Longitude & $2^{\circ} 25^{\prime} 734^{\prime \prime} \mathrm{E}$ \\
\hline
\end{tabular}

To determine the standard deviation of wind fluctuations, from the raw wind speed data we can separate the wind average speed of the turbulent flow. The raw wind speed is averaged with a time window from 30 minutes to 1 hour to obtain the mean wind speed (Ren et al. 2018). To determine the turbulent flow, we subtract the mean wind speed from the raw wind speed (Ren et al. 2018; Stull 1988). These different parameters are given from Eq. (2) to Eq. (4). The mean wind speed is obtained by:

$U=\frac{1}{n} \sum_{i=1}^{n} v_{i}$

where $n$ is the number of wind speed points in each time window. The turbulent flow $v^{\prime}$ is given therefore by:

$v^{\prime}=v-U$

The standard deviation $\sigma$ is expressed as follows (Ren et al. 2018; Mirhosseini et al. 2011):

$\sigma=\sqrt{\frac{1}{N-1} \sum_{i=1}^{N}\left(v_{i}-U_{i}\right)^{2}}$

$\mathrm{N}$ is the number of the wind speed observations. The turbulence intensity measured is therefore obtained from Eq. (1) to Eq. (4).

\subsubsection{The IEC Standards}

According to IEC 61400-2 relative to small wind turbine (rotor sweep area of less than $200 \mathrm{~m}^{2}$ ), the values of Normal Turbulence Model (NTM) standard deviation for wind speed, are given by the $90^{\text {th }}$ or $50^{\text {th }}$ percentile value of wind speed at the hub height (IEC 61400.2-2013):

$\sigma=\frac{I_{r e f}\left(15 m \cdot s^{-1}+a U\right)}{a+1}+\Delta \sigma$ 
$\mathrm{a}$ is the slope parameter for turbulence standard deviation model. $\mathrm{I}_{\text {ref }}$ represents characteristic value of turbulence intensity at wind speed $15 \mathrm{~m} / \mathrm{s} . \Delta \sigma=2(\mathrm{p}-1) \mathrm{I}_{\mathrm{ref}}, \mathrm{p}=0$ for the $50^{\text {th }}$ percentile, and $\mathrm{p}=1.28$ for the $90^{\text {th }}$ percentile. In order to compare the calculated $\sigma$ and I with the NTM, the values of $\sigma$ and I must be first determined from the wind speed data. This is done by assuming: the $50^{\text {th }}$ percentiles of $\sigma$ represents for each bin the average values of $\sigma\left(\sigma_{50}=\sigma_{\text {ave }}\right)$. On the other hand the $90^{\text {th }}$ percentiles is defined as the sum of $\sigma_{\text {ave }}$ values and 1.28 times standard deviation of $\sigma\left(\sigma_{90}=\sigma_{\text {ave }}+1.28 \sigma_{\sigma}\right)$. From Eq. (1) and Eq. (5), the turbulence intensity of the IEC is calculated. Table 3 presents the basic parameters defined in these standards.

Table 3

Basic parameters for SWT turbines classes (IEC 61400.2-2013)

\begin{tabular}{cccccc}
\hline & \multicolumn{5}{c}{ IEC 61400-2 (SWT) } \\
\hline Class & I & II & III & IV & S \\
\hline $\mathrm{I}_{\text {ref }}$ & 0.18 & 0.18 & 0.18 & 0.18 & Values \\
$\mathrm{V}_{\text {ref }}$ & 50 & 42.5 & 37.5 & 30 & specified by \\
$\bar{V}$ & 10 & 8.5 & 7.5 & 6 & manufacture \\
$\mathrm{A}$ & 2 & 2 & 2 & 2 & \\
\hline
\end{tabular}

$\mathrm{V}_{\text {ref }}$ is the reference wind speed average over $10 \mathrm{~min}$ $(\mathrm{m} / \mathrm{s})$. This is the basic parameter of the wind speed used to define wind turbine classes. This is the maximum extreme wind speed over $10 \mathrm{~min}$ with a 50 -year recurrence period for which the SWT designed to withstand climates is less than or equal to $V_{\text {ref }}\left(V_{\text {conception }} \leq V_{\text {ref }}\right)$.

\subsubsection{Analytical modelling of wind turbulence intensity}

From the studies of Cheung et al. (2016) the new formulations of the turbulence intensity estimation model were developed using the turbulent boundary layer theory. We therefore consider for this purpose the transport equation of turbulent kinetic energy $I_{g}$ (Cheung et al. 2016).

$$
\frac{\partial I_{g}}{\partial t}=\nabla \cdot\left(\frac{\nu_{t}}{\sigma_{k}} \nabla I_{g}\right)+\mathcal{P}-\varepsilon
$$

where $v_{t}$ is the turbulent viscosity, $\sigma_{k}$ a constant turbulent Prandtl number, $\mathcal{P}$ is the turbulent kinetic energy production and $\varepsilon$ the dissipation rate. The turbulent kinetic energy production and the dissipation rate are given by (Pope 2000):

$\mathcal{P}=\tau I_{g}^{\frac{1}{2}} l_{M B}\left(\frac{\partial U}{\partial Z}\right)^{2}$

$\varepsilon=\frac{\xi I_{g}^{\frac{3}{2}}}{l_{M B}}$

$\mathrm{l}_{\mathrm{MB}}$ is the length scale $(\mathrm{m})$ in the middle part of the atmospheric boundary layer, $\xi$ and $\tau$ are constant, $\mathrm{z}$ is the height above the ground, $\frac{\partial \mathrm{U}}{\partial \mathrm{Z}}$ is the average profile of wind shear.

Near the surface of the boundary layer, the terms of convection and kinetic energy scattering can be neglected (Cheung et al. 2016) into Eq. (6). From this hypothesis, the turbulent kinetic energy $I_{g}$ is expressed by:
$I_{g}=\frac{\tau l_{M B}^{2}}{\xi}\left(\frac{\partial U}{\partial Z}\right)^{2}$

According to the studies of Darbieu et al. (2014) $I_{g}$ is also expressed as a function of the wind fluctuation:

$I_{g}=\frac{1}{2}\left({\sigma_{u}}^{2}+{\sigma_{v}}^{2}+{\sigma_{w}}^{2}\right)$

$I_{g}$ is in $\left(\mathrm{m}^{2} \cdot \mathrm{s}^{-2}\right), \sigma_{u}{ }^{2}$ is the variance of longitudinal wind component $\left(\mathrm{m}^{2} . \mathrm{s}^{-2}\right), \sigma_{v}{ }^{2}$ is the variance of transversal wind component $\left(\mathrm{m}^{2} \cdot \mathrm{s}^{-2}\right), \sigma_{w}{ }^{2}$ is the variance of vertical wind component $\left(\mathrm{m}^{2} \cdot \mathrm{s}^{-2}\right)$. In considering Eq. (9) and Eq. (10), the horizontal wind fluctuation $\sigma$ can vary as (Cheung et al. 2016):

$\sigma=\sigma_{0}+\tau_{0} l_{M B}\left(\frac{\partial U}{\partial Z}\right)$

From Eq. (11), the turbulence intensity can be modelled by (Cheung et al. 2016):

$I=I_{0}+\frac{\sigma}{U}$

$\sigma_{0}, \tau_{0}$ and $I_{0}$ are a constant for calibration purposes. According to the studies of Panofsky (1973), Gryning et al. (2007), Peña et al. (2008), the average profile of wind shear for an homogeneous and stationary flow in the surface layer can be written as:

$\frac{\partial U}{\partial Z}=\frac{u_{*}}{\kappa l_{S L}} \phi_{m}$

$u_{*}$ is the local friction velocity $(\mathrm{m} / \mathrm{s}), \kappa$ is the von-Karman constant $(\approx 0.4), l_{S L}$ is the local length scale $(\mathrm{m})$ in the surface layer (SL), $\phi_{m}$ is the function of the atmospheric stability correction, also known as the dimensionless wind shear. On this surface, which accounts for the lowest $10 \%$ of the Atmospheric Boundary Layer (ABL), the variation of $\mathrm{u}_{*}$ with altitude is neglected, and the length scale is assumed to be equal to the height (Peña et al. 2008).

$u_{*}=u_{* 0}$

$l_{S L}=\mathrm{z}$

where $u_{* 0}$ is the friction velocity, $\mathrm{z}$ is altitude. The friction velocity has been determined in our study site in the studies of Donnou et al. (2019c). The studies of Businger et al. (1971), Dyer (1974), and Högström (1988) suggested the following expressions of $\phi_{m}$ for unstable, neutral and stable atmospheric conditions:

$\phi_{m}=\left(1+\gamma_{0} \frac{z}{L}\right)^{p_{0}}$

$\phi_{m}=1$

$\phi_{m}=\left(1+\beta_{0} \frac{z}{L}\right)$

where $\gamma_{0}, \beta_{0}, p_{0}$ are a constant for calibration purposes. L is Obukhov length $(\mathrm{m})$. This parameter has been determined in the studies of Donnou et al. (2019a) on the 
site of Cotonou. According to the studies of Gryning et al. (2007), the wind profile length scale is composed of three component length scales $\left(l_{S L}, l_{M B}, l_{U B}\right)$. And in the surface layer, the first length scale $l_{S L}$ is taken to increase linearly with height. Above the surface layer the second length scale is $l_{M B}$. Little is known about the behaviour of the length scale $l_{U B}$ in the upper part and near the top of the boundary layer (Gryning et al. 2007). It is assumed to be equal to the distance to the top of the ABL (Peña et al. 2008). The data used in this study are at $10 \mathrm{~m}$ above the ground, so in the surface layer. We can therefore use $l_{S L}$ into Eq (7) and Eq (8) at instead of $l_{M B}$. From the Eq (11) to Eq. (13), the Eq. (12) becomes:

$I=I_{0}+\frac{\sigma_{0}+\tau_{0} l_{S L}\left(\frac{u_{* 0}}{\kappa z} \phi_{m}\right)}{U}$

On our study site, the power law is one of the best law for the fitting of wind speed profile according to the studies of Donnou et al. (2019a) the Eq. (19) can be also expressed by :

$$
I=I_{0}+\left[\sigma_{0}+\tau_{0} l_{S L}\left(\frac{u_{*}}{\kappa z} \phi_{m}\right)\right] U^{-\mu_{0}}
$$

where $\mu_{0}$ is a constant for calibration purposes. In considering the studies of Donnou et al. (2019c) performed in the same study area, the turbulence intensity is expressed like an increasing linear function of roughness length $z_{0}$ :

$\frac{\sigma_{0}}{U}=a_{0} z_{0}+b_{0}$

$a_{0}$ and $b_{0}$ are a constant for calibration purposes. Eq. (20) becomes:

$$
I=a_{0} z_{0}+b_{01}+\tau_{0} l_{S L}\left(\frac{u_{*}}{\kappa z} \phi_{m}\right) U^{-\mu_{0}}
$$

$b_{01}$ is a constant for calibration purposes. The roughness length has been determined from the Charnock model and calculated in the studies of Donnou et al. (2019c) This model (Eq. (22)) is a function of the wind speed, the friction velocity, the roughness length, the local length scale in the surface layer and the atmosphere stability. It is the first model (model 1) of turbulence intensity proposed in this study.

In the studies of Cheung et al. (2016), the authors have assimilated the average profile of wind shear like a function of power law. In this study, we have rather assuming that, $\frac{\partial U}{\partial Z}$ can be expressed like a function of the wind shear coefficient $\alpha$ :

$$
\frac{\partial U}{\partial Z}=\delta \alpha
$$

$\delta$ is a constant. Another model of the turbulence intensity has been therefore proposed. Thus, the Eq. (22) gives:

$$
I=a_{0} z_{0}+b_{01}+\tau_{1} l_{S L} \alpha U^{-\mu_{0}}
$$

Several expressions relating to the wind shear coefficient determination are encountered in the literature. Referring to the studies of Newman and Klein (2014), the Eq. (25) is used by authors to determine the wind shear coefficient:

$\alpha=\alpha_{0}\left(1+\beta_{1} R_{i}\right)^{p_{1}}$

$\tau_{1}, \beta_{1}$ and $p_{1}$ are a constant for calibration purposes. $R_{i}$ is the Richardson number and is also a stability parameter of atmosphere. So we can modify the Eq. (25) by introducing the Obukhov length to replace $R_{i}$ :

$$
\alpha=\alpha_{0}\left(1+\beta_{1} L\right)^{p_{1}}
$$

$\alpha_{0}$ is given by Spera and Richards (1979):

$\alpha_{0}=\left(\frac{z_{0}}{z}\right)^{h_{0}}$

$h_{0}$ is a constant for calibration purposes. From Eq. (24) and Eq. (26), the second model (model 2) proposed is expressed as follows:

$$
I=a_{1} z_{0}+b_{1}+\tau_{1} l_{S L} \alpha_{0}\left(1+\beta_{1} L\right)^{p_{1}} U^{-\mu_{1}}
$$

$a_{1}, b_{1}, \tau_{1}$ and $\mu_{1}$ are a constant for calibration purposes. This model is a function of roughness length, the wind speed, the local length scale in the surface layer and atmospheric stability. The studies of Dimitrov et al. (2015) have given another expression of wind shear coefficient function of wind speed:

$\alpha=a[\ln (U)-d]$

a and $\mathrm{d}$ are a constant for calibration purposes. The third model (model 3) is derived from Eq. (24) and Eq. (29). It is a function of roughness length, wind speed and the local length scale in the surface layer:

$I=a_{2} z_{0}+b_{2}+\tau_{2} l_{S L}[\ln (U)-d] U^{-\mu_{2}}$

$a_{2}, b_{2}, d, \tau_{2}$ and $\mu_{2}$ are a constant for calibration purposes. The studies of Smedman-Högström and Högström (1983) proposed the following expression to determine the wind shear coefficient:

$\alpha=c_{0}+c_{1} \log \left(z_{0}\right)+c_{2}\left(\log z_{0}\right)^{2}$

$c_{0}, c_{1}, c_{2}$ are a constant for calibration purposes. The fourth model (model 4) proposed comes from Eq. (24) and Eq. (31):

$$
I=a_{3} z_{0}+b_{3}+\tau_{3} l_{S L}\left[c_{0}+c_{1} \log \left(z_{0}\right)+c_{2}\left(\log \left(z_{0}\right)\right)^{2}\right] U^{-\mu_{3}}
$$

$a_{3}, b_{3}, \tau_{3}$ and $\mu_{3}$ are a constant for calibration purposes. It is a function of roughness length, the wind speed and the local length scale in the surface layer. The studies of Gualtieri (2015) proposed as for them a relationship between $\alpha$ and $I$ :

$\alpha=k_{1} \ln (I)+k_{0}$ 
where $k_{1}$ and $k_{0}$ are a constant for calibration purposes. In replacing Eq. (33) into Eq. (24) and after a changing of variable, we have the following expression:

$A I+B=\left[k_{1} \ln (I)+k_{0}\right] U^{-\mu_{4}}$

where:

$$
\begin{aligned}
& A=\frac{1}{\tau_{4} l_{S L}} \\
& B=-\left(\frac{a_{4} z_{0}+b_{4}}{\tau_{4} l_{S L}}\right)
\end{aligned}
$$

$a_{4}, b_{4}, \tau_{4}$ and $\mu_{4}$ are a constant for calibration purposes The resolution of Eq. (34) has been obtained from the command "solve" developed under Matlab. The solution is given by:

$$
I=-A U^{-\mu_{4}} k_{1} \omega\left[-\ln \left(-k_{1} A U^{-\mu_{4}}\right)-\left(\frac{k_{0}-B U^{\mu_{4}}}{k_{1}}\right)\right]
$$

where $\omega$ is Wright omega Function. The Wright $\omega$ function is a single-valued function, defined in terms of the Lambert $W$ function (Corless and Jeffrey 2002). It is defined as follows:

$\omega(x)=W_{\kappa(x)} \exp (x)$

and:

$$
\kappa(x)=\left[\frac{(\operatorname{Im}(x)-\pi)}{(2 \pi)}\right]
$$

The fifth model (model 5) of turbulence intensity proposed is therefore given by Eq. (36). It is a function of wind speed, the roughness length, the local length scale in the surface layer and Wright omega Function. These five new models have been assessed on the site from the data of the turbulence intensity. The different constant of these models have been determined by numerical simulation in order to better calibrate the models. The simulation method adopted is presented in the following section.

\subsubsection{Numerical simulation}

The simplex algorithm of Nelder and Mead (Nelder and Mead 1965) one of the most widely adopted methods for non-linear unconstrained optimization, has been used in this study in order to better calibrate the models proposed. In the software Matlab it is the function fminsearch which have been used to simulate this algorithm. Fminsearch finds the minimum of a scalar function of several variables, starting by an initial estimate. This is generally referred to as unconstrained non-linear optimization. It uses the simplex search method of Lagarias et al. (1998). This is a direct search method that does not use numerical or analytic gradients:

- If $t$ is the length of $x$, a simplex in n-dimensional space is characterized by the $t+1$ distinct vectors that are its vertices. In two-space, a simplex is a triangle; in three-space, it is a pyramid.
- At each step of the search, a new point in the simplex or near the current simplex is generated. The function value at the new point is compared with the function's values at the vertices of the simplex and, usually, one of the vertices is replaced by the new point, giving a new simplex.

- This step is repeated until the diameter of the simplex is less than the specified tolerance.

\subsubsection{Statistical test.}

Mean Absolute Error (MAE) and Root mean squared error (RMSE) are two of the most common estimators used to evaluate the errors committed by the prediction. The MAE is the average over the test sample of the absolute differences between prediction and actual observation where all individual differences have equal weight. The RMSE is a quadratic scoring rule that also measures the average magnitude of the error. It's the square root of the average of squared differences between prediction and actual observation. These two error estimations are given by Amar et al. (2008), Chai and Draxler (2014):

$$
\begin{aligned}
& R M S E=\sqrt{\frac{1}{N} \sum_{i=1}^{N}\left(p_{i}-f_{i}\right)^{2}} \\
& M A E=\frac{1}{N} \sum_{i=1}^{N}\left|\left(p_{i}-f_{i}\right)\right|
\end{aligned}
$$

Where $p_{i}$ represents observations, $f_{i}$ the different estimates or predictions and $\mathrm{N}$ the number of the wind speed observations. The smaller its value is, the closer it is to zero and the better the model is.

\section{Results and Discussions}

\subsection{Turbulence intensity as function of wind speed: IEC standards}

3.1.1. Instantaneous wind speed, mean wind speed and turbulent flow

Fig. 3 shows the raw wind speed time series of June 2011 to April 2014. The raw wind speed time series have been averaged with a time window of $1 \mathrm{~h}$ to obtain the mean wind speed and turbulent flow, as shown in Fig. 4.

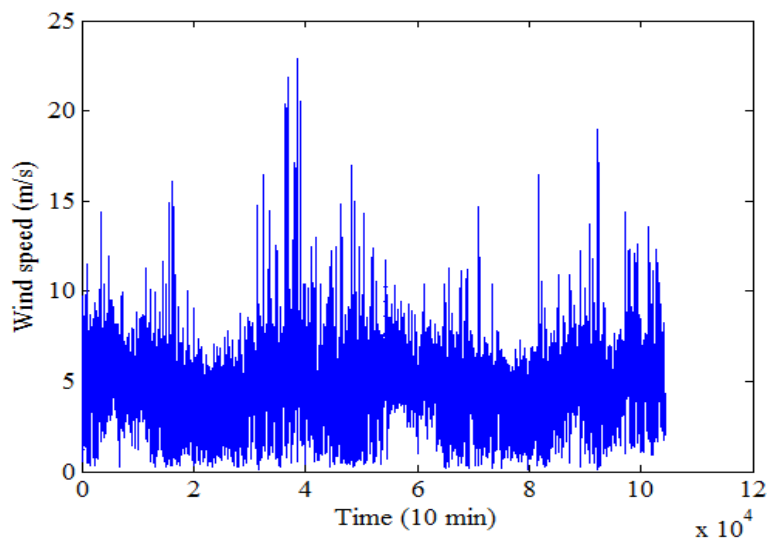

Fig. 3 Ten-minute wind speed time series from June 2011 to April 2014. 

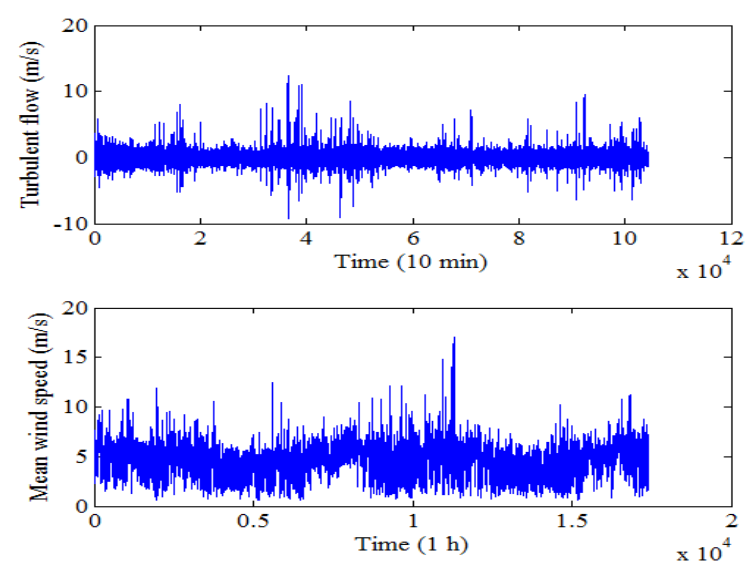

Fig. 4 Average speed of wind and turbulent flow time series from June 2011 to April 2014.
We noticed on the Figs. 3 and 4 that the raw wind speed varies from 0 to $22.8 \mathrm{~m} / \mathrm{s}$. The turbulent flow fluctuates between $-9.30 \mathrm{~m} / \mathrm{s}$ and $12.5 \mathrm{~m} / \mathrm{s}$. The average speed of wind in the time window of $1 \mathrm{~h}$ varies from 0.57 to $17.05 \mathrm{~m} / \mathrm{s}$.

\subsubsection{Assessment of IEC standard with actual turbulence intensity}

The variations of standard deviation with the wind speed for the case Iref standard (Fig. 5(a)) and Iref measured (Fig. 5(b)) are shown on the Fig 5. The measured standard deviation is an increasing function of the wind speed. However $\sigma$ is not linear as specified in the IEC model standard. This result is in line with the studies of Ren et al. (2018) and Wang et al. (2013). It is also obvious that $\sigma$ evolves more rapidly with wind speeds greater than $12 \mathrm{~m} / \mathrm{s}$ and slowly with wind speeds below $8 \mathrm{~m} / \mathrm{s}$.

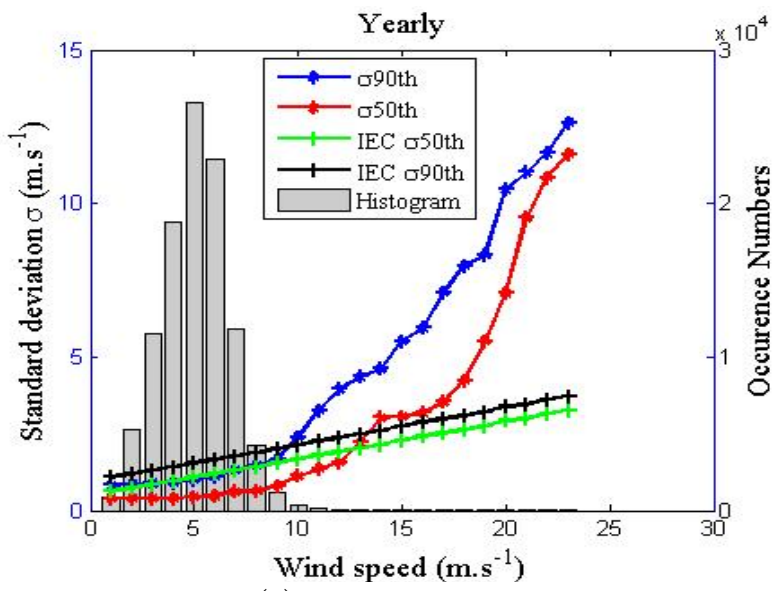

(a)

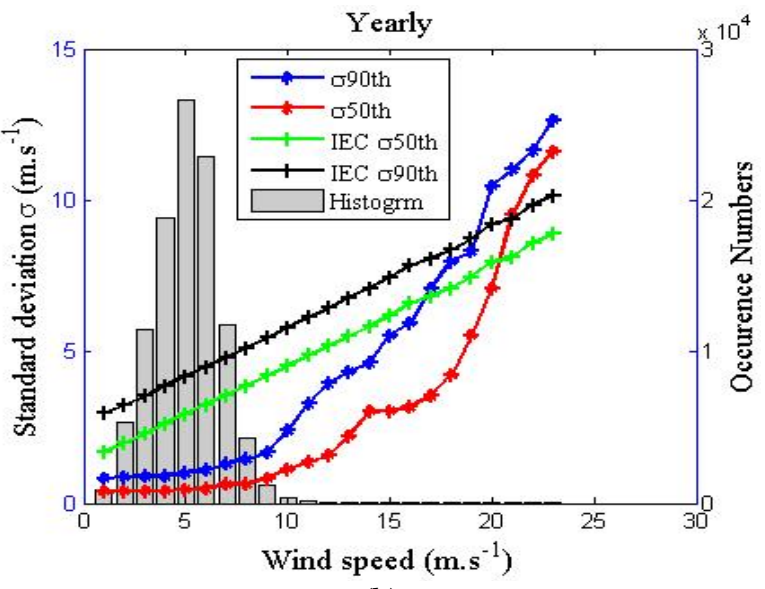

(b)

Fig. 5 Annual variation of standard deviation as a function of wind speed at $10 \mathrm{~m}$. The $50^{\text {th }}$ and $90^{\text {th }}$ percentile of $\sigma$ are represented. a) $I_{\text {ref }}=0.18$ (standard value IEC) is used in left panel and b) $I_{\text {ref }}=0.50$ (measure value) is used in right panel.

For weak winds, the standard deviation is almost constant. We also noticed that the most frequent wind speeds on this site, have a standard deviation that does not exceed $1 \mathrm{~m} / \mathrm{s}$. Table 4 presents the values of the error estimators between the measured and the estimated standard deviations. There is therefore a large gap between the measurements and the estimates. Moreover, when we use the reference turbulence intensity $I_{\text {ref }}$ measured on our site to estimate the standard deviation from the IEC standard, we notice that the error estimators are lower than in the standard $I_{r e f}$ case. These results therefore confirm the inadequacy of the IEC standard model for estimating the standard deviation of wind speeds on our site.

Table 4

Errors estimations between the measured standard deviation and standard deviation model of IEC.

\begin{tabular}{ccccccccc}
\hline & \multicolumn{3}{c}{$I_{\text {ref }}$ (Standard value) } & \multicolumn{3}{c}{$I_{\text {ref }}$ (Measured value) } \\
\cline { 2 - 9 } Period & \multicolumn{2}{c}{ IEC $\sigma 90$ th } & \multicolumn{2}{c}{ IEC $\sigma 50$ th } & \multicolumn{2}{c}{ IEC $\sigma 90$ th } & \multicolumn{2}{c}{ IEC $\sigma 50$ th } \\
\hline \multirow{2}{*}{ Annual } & MAE & RMSE & MAE & RMSE & MAE & RMSE & MAE & RMSE \\
& 2.7007 & 3.8867 & 1.7910 & 2.9906 & 2.3518 & 2.5377 & 1.7077 & 1.9167 \\
\hline
\end{tabular}

On the Figs. 6 and 7, we present the monthly and annual variations of wind turbulence intensity as a function of wind speed. The different classes of atmosphere stability and when these conditions of stability are not taking into account have been explored.
The intensity of the turbulence $I_{U}$ calculated from Eq. (1) and Eq. (4) and the turbulence model of the IEC standard obtained by Eq. (1) and Eq. (5) are presented in the Figs. 6 and 7. 
Citation: Donnou, H.E.V., Akpo, A.B., Houngue, G.H. and Kounouhewa, B.B. (2020) Assessment of IEC Normal Turbulence Model and Modelling of the Wind Turbulence Intensity for Small Wind Turbine Design in Tropical Area: Case of the Coastal Region of Benin. Int. Journal of Renewable Energy Development, 9(2), 263-286, doi: 10.14710/ijred.263-286 P a g e 1270
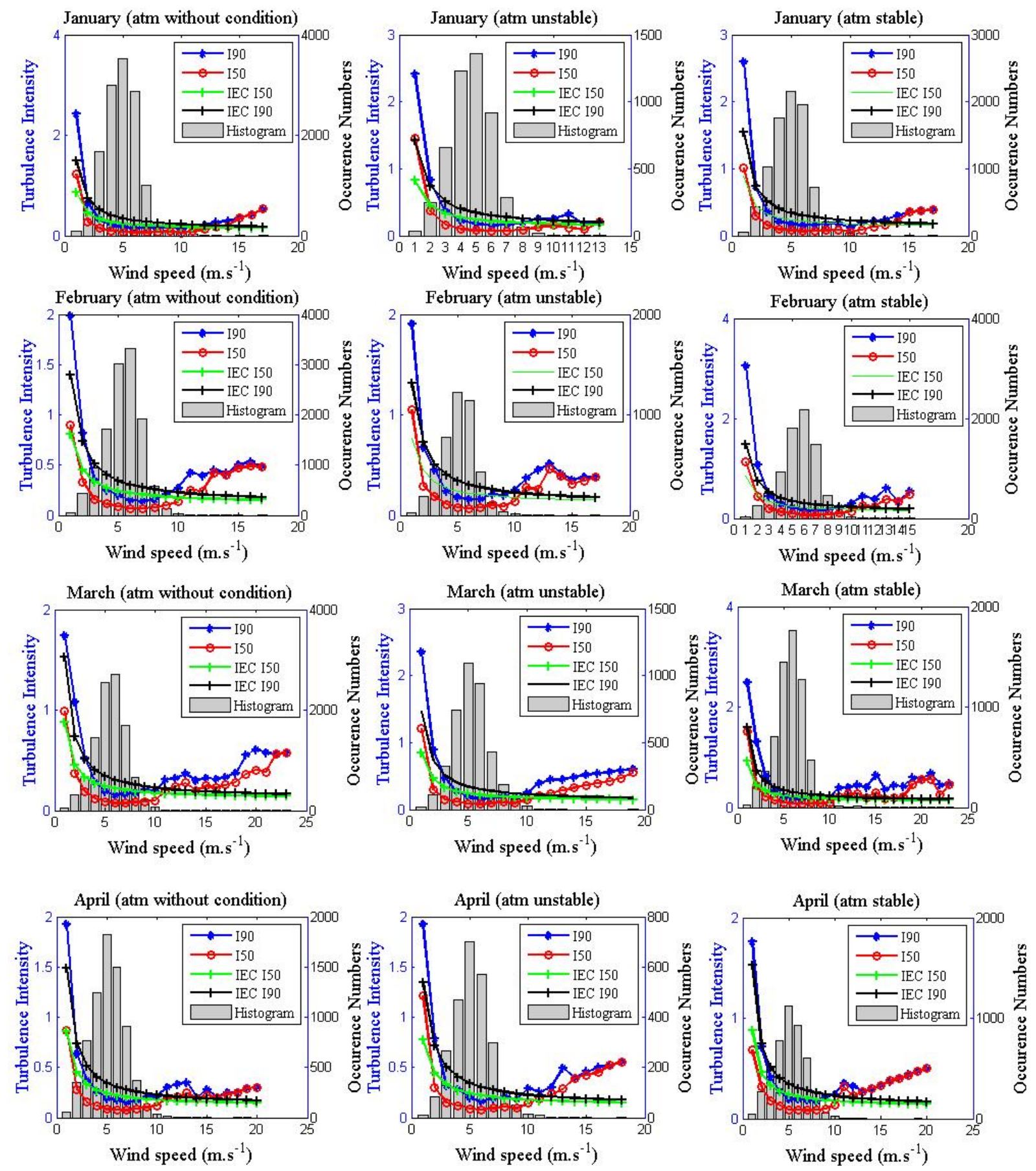

Fig. 6 Monthly variation of turbulence intensity as a function of wind speed at $10 \mathrm{~m}$. The $50^{\text {th }}$ and $90^{\text {th }}$ percentile of $I_{U}$ are represented. The value of the reference turbulence intensity used is $I_{\text {ref }}=0.18$ (standard value). 

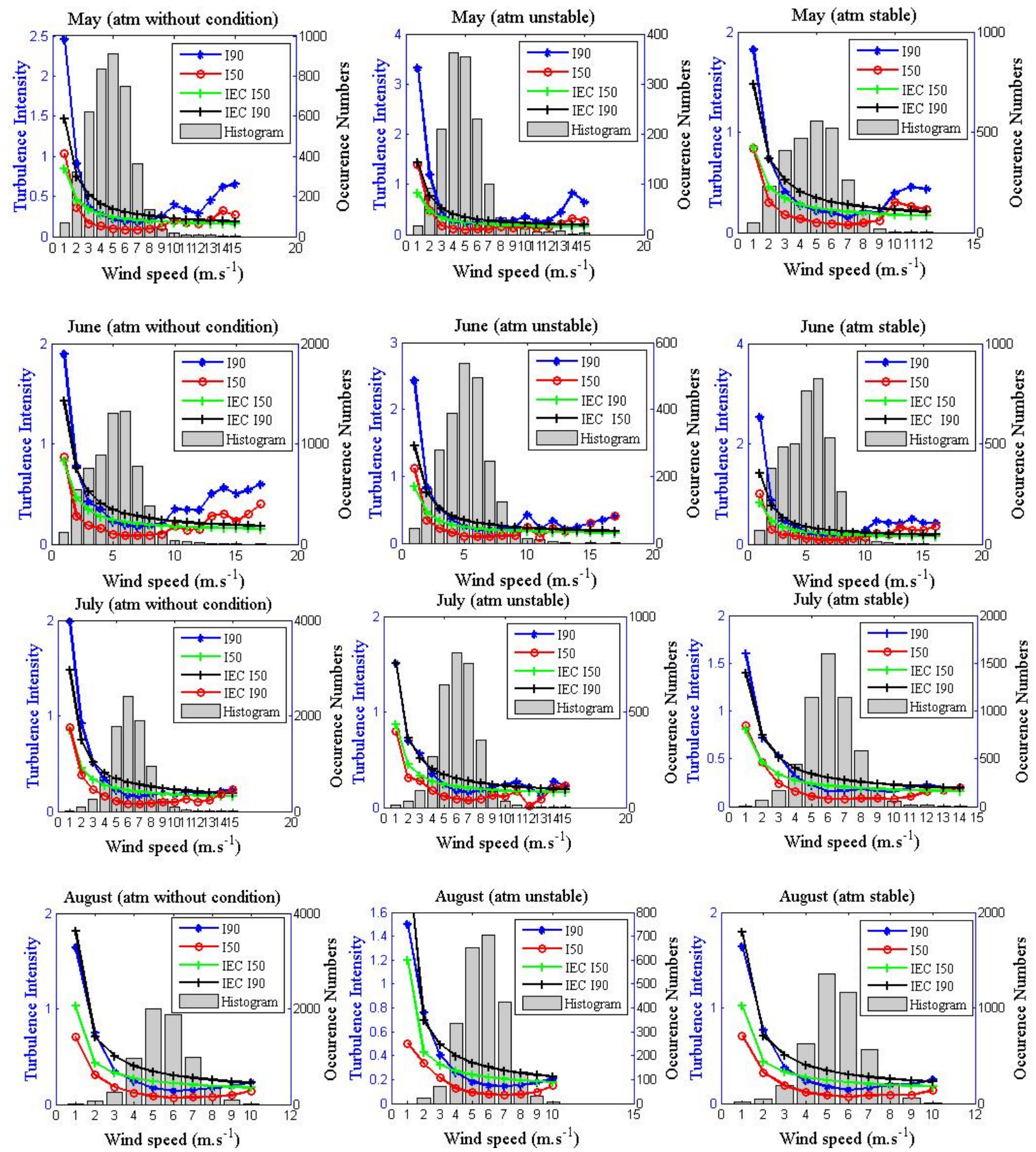

Fig. 6 Monthly variation of turbulence intensity as a function of wind speed at $10 \mathrm{~m}$. The $50^{\text {th }}$ and $90^{\text {th }}$ percentile of $I_{U}$ are represented. The value of the reference turbulence intensity used is $I_{r e f}=0.18$ (standard value). (Cont..) 
Citation: Donnou, H.E.V., Akpo, A.B., Houngue, G.H. and Kounouhewa, B.B. (2020) Assessment of IEC Normal Turbulence Model and Modelling of the Wind Turbulence Intensity for Small Wind Turbine Design in Tropical Area: Case of the Coastal Region of Benin. Int. Journal of Renewable Energy Development, 9(2), 263-286, doi: 10.14710/ijred.263-286 $\mathrm{P}$ a g e 1272
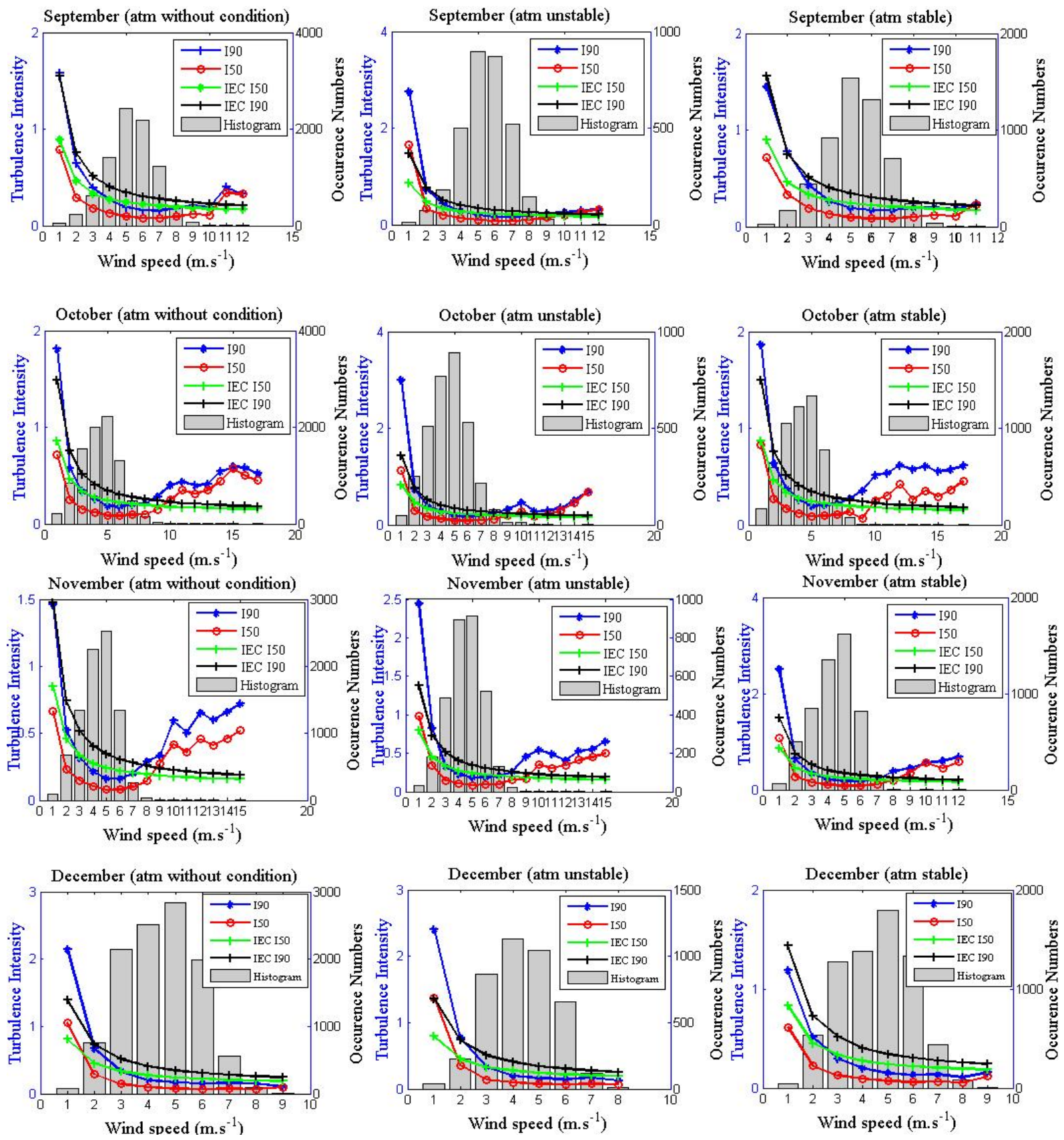

Fig. 6 Monthly variation of turbulence intensity as a function of wind speed at $10 \mathrm{~m}$. The $50^{\text {th }}$ and $90^{\text {th }}$ percentile of $I_{U}$ are represented. The value of the reference turbulence intensity used is $I_{r e f}=0.18$ (standard value).(Cont...)
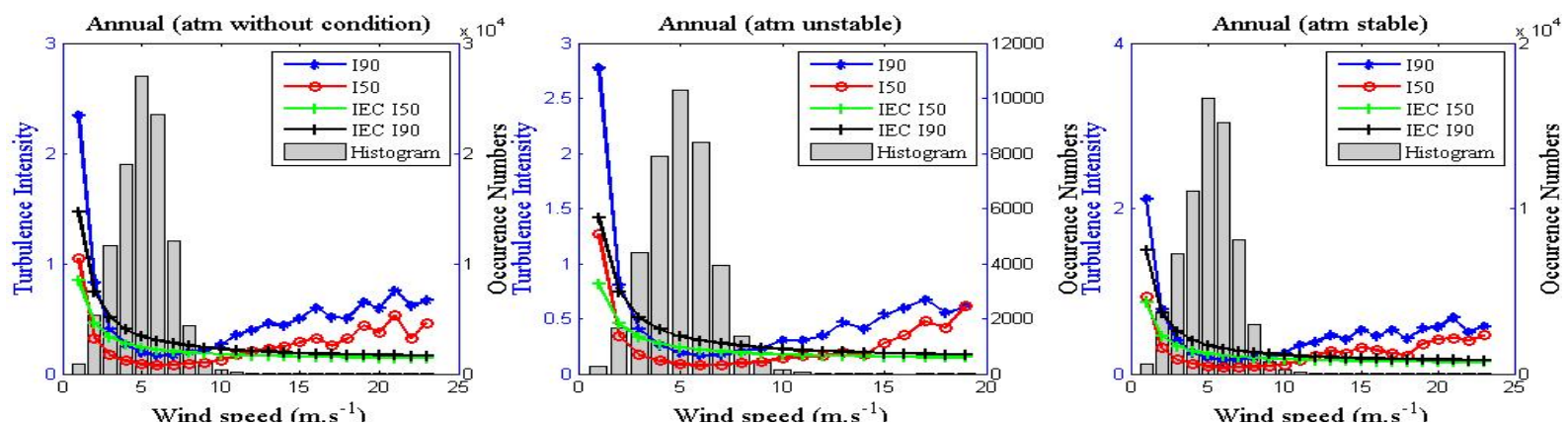

Wind sneed $\mathrm{rm}_{\mathrm{s}} \mathrm{s}^{-1} \mathrm{Y}$
Fig. 7 Annual variation of turbulence intensity as a function of wind speed at $10 \mathrm{~m}$. The $50^{\text {th }}$ and $90^{\text {th }}$ percentile of $\mathrm{s}^{\mathrm{s}} I_{U}$ are represented for the data and the IEC standard. The value of the reference turbulence intensity used is $I_{\text {ref }}=0.18$ (standard value). 
During the year, and depending on the wind speed range, the wind turbulence intensity varies differently according to the months and the classes of the atmosphere stability. It is noted that whatever the atmosphere stability conditions, the turbulence intensity decreases from low wind speeds $(0-1 \mathrm{~m} / \mathrm{s})$ to reach a threshold value ranging from 7 to $13 \mathrm{~m} / \mathrm{s}$ depending on the period of the year. The most frequent wind speeds on the site correspond to the decreasing phase of wind turbulence intensity. The highest values of $I_{U}$ on our study site correspond to the low wind speeds $(0-1 \mathrm{~m} / \mathrm{s})$ would be due to the thermal turbulence as stipulated in the work of Wang et al. (2013) These high values observed between $0-1 \mathrm{~m} / \mathrm{s}$ do not, however, hinder the good operation of small wind turbines whose starting speed is similar to $2-3 \mathrm{~m} / \mathrm{s}$. Beyond the threshold values, which correspond to moderate wind speeds, we noticed an increase of the distribution of the turbulence intensity during a good period of the year. This observation would be due to the mechanical turbulence (friction on the ground due to the roughness of the surface). The highest values of wind turbulence intensity $I_{50}$ observed for strong winds $(>13 \mathrm{~m} / \mathrm{s}$ ) are obtained during the months of February, March, April, October and November. We observed a peak of 0.68 obtained in October under an unstable atmosphere. For the $90^{\text {th }}$ percentile, these high values are obtained in February, March, April, May, June, October and November with a peak of 0.70 in November. The lowest values are recorded during the period of July-August. During these months, we could therefore say that the distribution of wind turbulence is not too influenced by the roughness above the ground. From all these analyzes, the intensity of the turbulence is not always therefore a decreasing function of the wind speed over the entire range of wind speeds observed on our site. It can increase after a threshold value of wind speed under the influence of the roughness. These findings are confirmed by the studies of Wang et al. (2013), Turk and Emeis (2010) which indicates that the roughness of the surface increases with the turbulence of the wind.

The estimation of the wind turbulence intensity from the IEC standard revealed an underestimation or an overestimation of the data depending on the wind speed range. During the months of January, February, March, April, May, June, September, October (atmosphere without condition), the IEC standard model underestimates measurements for wind speeds above 10 $\mathrm{m} / \mathrm{s}$, and at $8 \mathrm{~m} / \mathrm{s}$ in November. Between $2 \mathrm{~m} / \mathrm{s}$ and $10 \mathrm{~m} / \mathrm{s}$ or more depending on the period of the year, the standard IEC overestimates the measurements. For the months of July, August and December we can say that the model of the IEC standard overestimates the measurements over practically the whole range of wind speed. In September (unstable and stable atmosphere), the same remark has been pointed out. We also noticed that the characteristic value of the wind turbulence intensity $I_{\text {ref }}$, measured on the study site is different from that recommended by the IEC standard. This standard value evaluated at 0.18 according to the IEC standard varies from 0.223 in April to 0.54 in October on our study site. For the annual distribution presented on the Fig. 7, the model of the IEC standard underestimates $(v>12 \mathrm{~m} / \mathrm{s})$ or overestimates $(2$ $<v<9 \mathrm{~m} / \mathrm{s}$ ) the data. The values obtained for NTM model estimation errors at a monthly and annual scale are shown in Table 5. They indicate significant differences between the measurements and the estimates except the month of July (stable and unstable conditions) and September (stable conditions). The error estimators (MAE, RMSE) are respectively evaluated during these periods at $(0.0695 ; 0.0891),(0.0552 ; 0.0679)$ and $(0.0829$; $0.0946)$. These results thus confirm the inadequacy of normal turbulence model with the measurements. The use of this standard on our site for the design of wind turbines is therefore not appropriate. These results are consistent with the studies of Ren at al. (2018), Leu et al. (2014) Lopez-Villalobos et al. (2018), Ishihara et al. (2012), Wang et al. (2013), Carpman (2011) which also reached the same conclusion on their study site. Structural dysfunctions and significant damage could therefore occur during the operation of turbines designed from the turbulence levels generated by the IEC standard model in this region of the West Africa.

Table 5

Estimation error (RMSE; MAE) between the normal IEC turbulence model and the monthly and annual data. (2011-2014).

\begin{tabular}{cccccc}
\hline & \multicolumn{2}{c}{ IEC I90 } \\
\cline { 2 - 5 } & Atmosphere without condition & \multicolumn{2}{c}{ Stable Atmosphere } & \multicolumn{2}{c}{ Unstable Atmosphere } \\
\hline Jan & RMSE & MAE & RMSE & MAE & RMSE \\
Feb & 0.2724 & 0.1821 & 0.1449 & 0.1302 & 0.2924 \\
Mar & 0.2404 & 0.2017 & 0.1408 & 0.1632 & 0.2141 \\
Apr & 0.2308 & 0.1894 & 0.2153 & 0.1582 & 0.3109 \\
May & 0.3264 & 0.1105 & 0.1845 & 0.1656 & 0.2365 \\
Jun & 0.2358 & 0.2233 & 0.1671 & 0.1403 & 0.5459 \\
Jul & 0.1561 & 0.1898 & 0.3217 & 0.2030 & 0.2578 \\
Aug & 0.1282 & 0.0965 & 0.0891 & 0.0695 & 0.1892 \\
Sep & 0.1145 & 0.1134 & 0.1210 & 0.1086 & 0.2975 \\
Oct & 0.2365 & 0.1043 & 0.0946 & 0.0829 & 0.1361 \\
Nov & 0.2906 & 0.2091 & 0.2826 & 0.2457 & 0.1555 \\
Dec & 0.2832 & 0.2429 & 0.3368 & 0.2818 & 0.3770 \\
Ann & 0.3447 & 0.2083 & 0.1820 & 0.1881 & 0.4443 \\
\end{tabular}



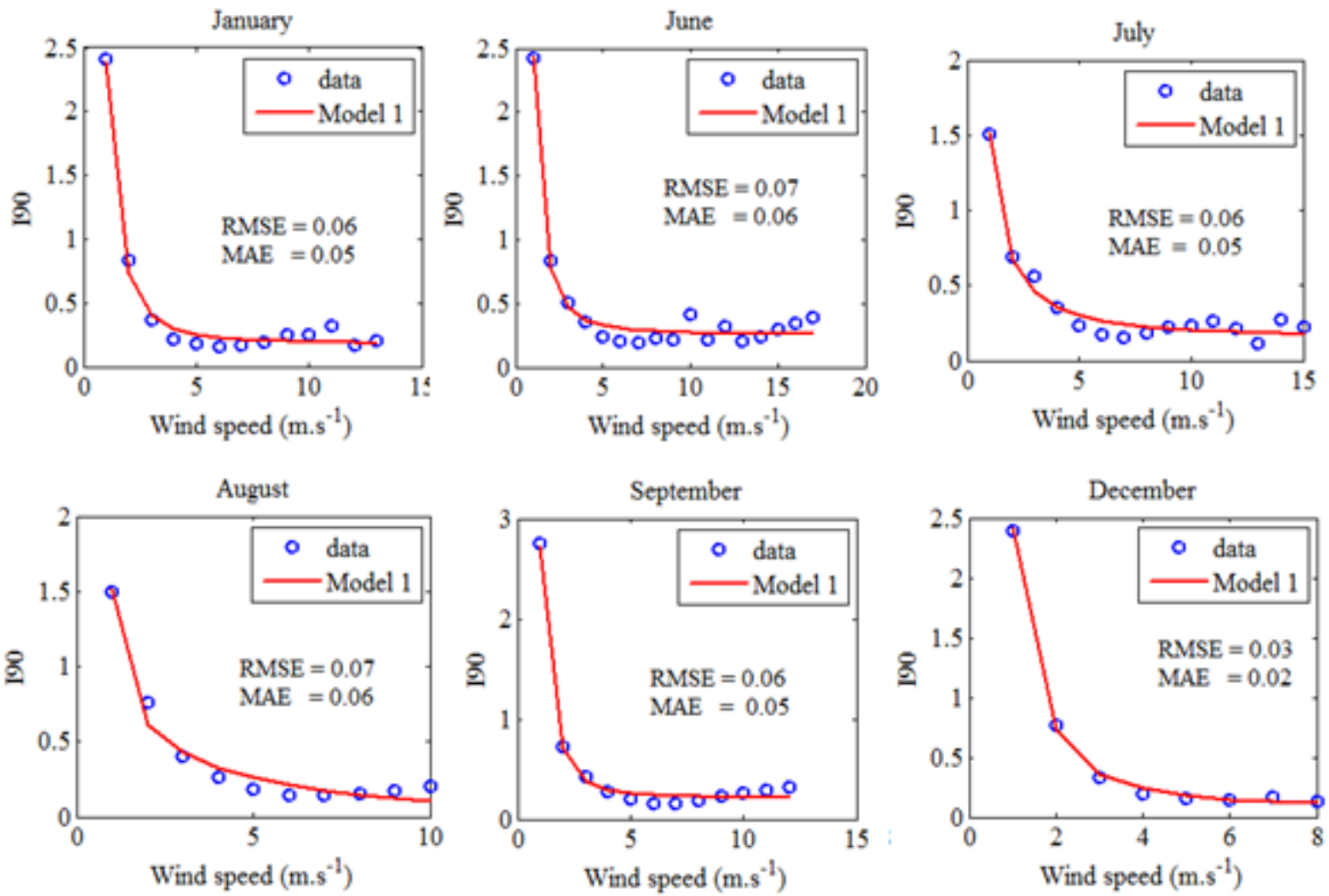

Fig. 8 Evaluation of the proposed model 1 with turbulence intensity data under unstable atmosphere condition à 10 m. (2011-2014).
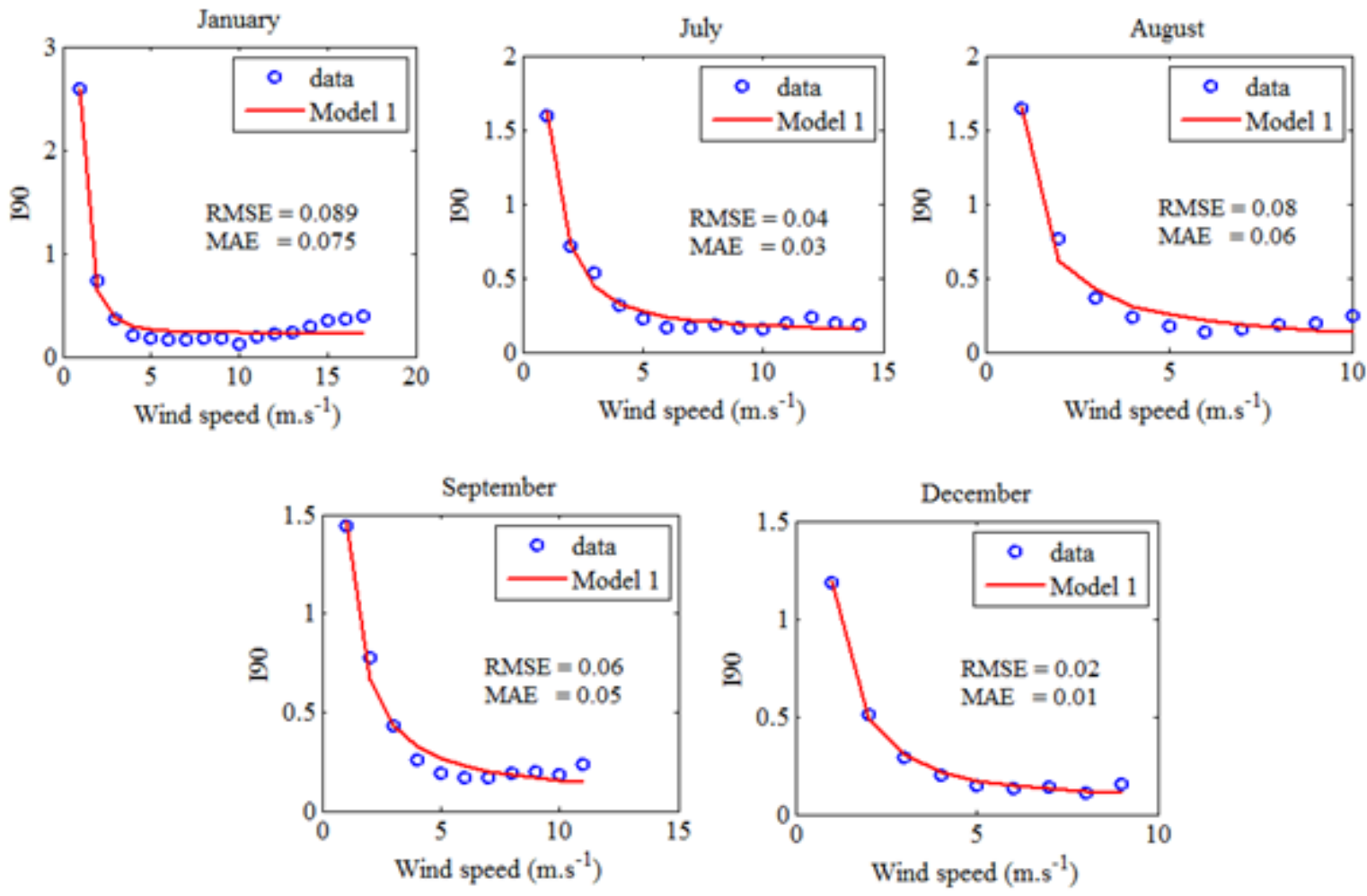

Fig. 9 Evaluation of the proposed model 1 with turbulence intensity data under stable atmosphere conditions à 10 m (2011-2014). 


\subsection{Numerical simulation of new turbulence intensity} models

\subsubsection{Turbulence intensity simulation from the analytical models}

The Figs. 8-12 present the simulations results of the different models for estimating the intensity of wind turbulence proposed in this study. From the calculated I 90 values, the five models proposed will be simulated to better calibrate them to the data. On the Figs 8 and 9, the simulations of the model 1 have been carried out as a function of the atmosphere stability conditions. According to the studies of Donnou et al. (2019a) in the study area, the atmosphere is unstable between 09:00 and 18:00 UTC and stable the rest of the time. Wind data were therefore handled separately for these two periods.

On the Fig. 8 (unstable atmosphere), we noticed that only for the months of January, June, July, August, September and December, the model suitably reproduces the measurements of the intensity of wind turbulence when the atmosphere is unstable. The error estimators (MAE, RMSE) are higher for these months and range from
$(0.09 ; 0.11)$ in February to $(0.15 ; 0.16)$ in November. For the stable conditions (Fig. 9), and during the months of January, July, August, September and December, low MAE and RMSE values are obtained and range from (0.01; 0.02) in December to $(0.089 ; 0.075)$ in January. The performance of the model is therefore better during these periods of the year.

In short, model 1 gives a good result for the months when the distribution of turbulence intensity decreases on the entire range of wind speeds. This model cannot reproduce the growth sequences of the wind turbulence intensity. It is therefore more suitable on the sites where wind turbulence is a decreasing function of wind speed. It is also important to note that the simulations of the proposed model 2 which is also a function of the stability of the atmosphere gave the same performances as the model 1 after simulation, with different values of the calibration constants. The results of this simulation were therefore not presented in this study. On Fig. 10, the performance of the proposed model 3 were examined.
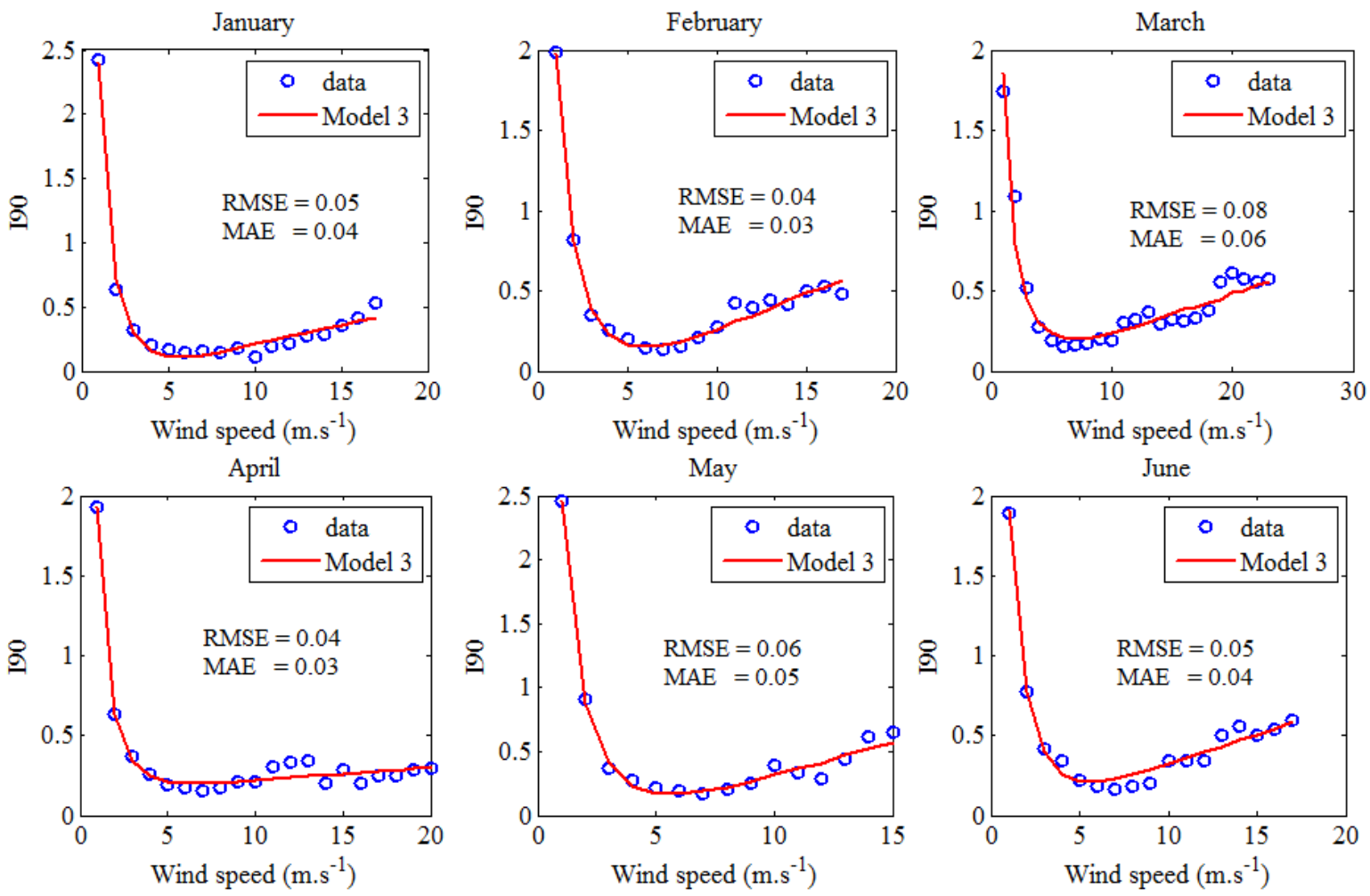

Fig. 10 Evaluation of the proposed model 3 with turbulence intensity data (2011-2014) 

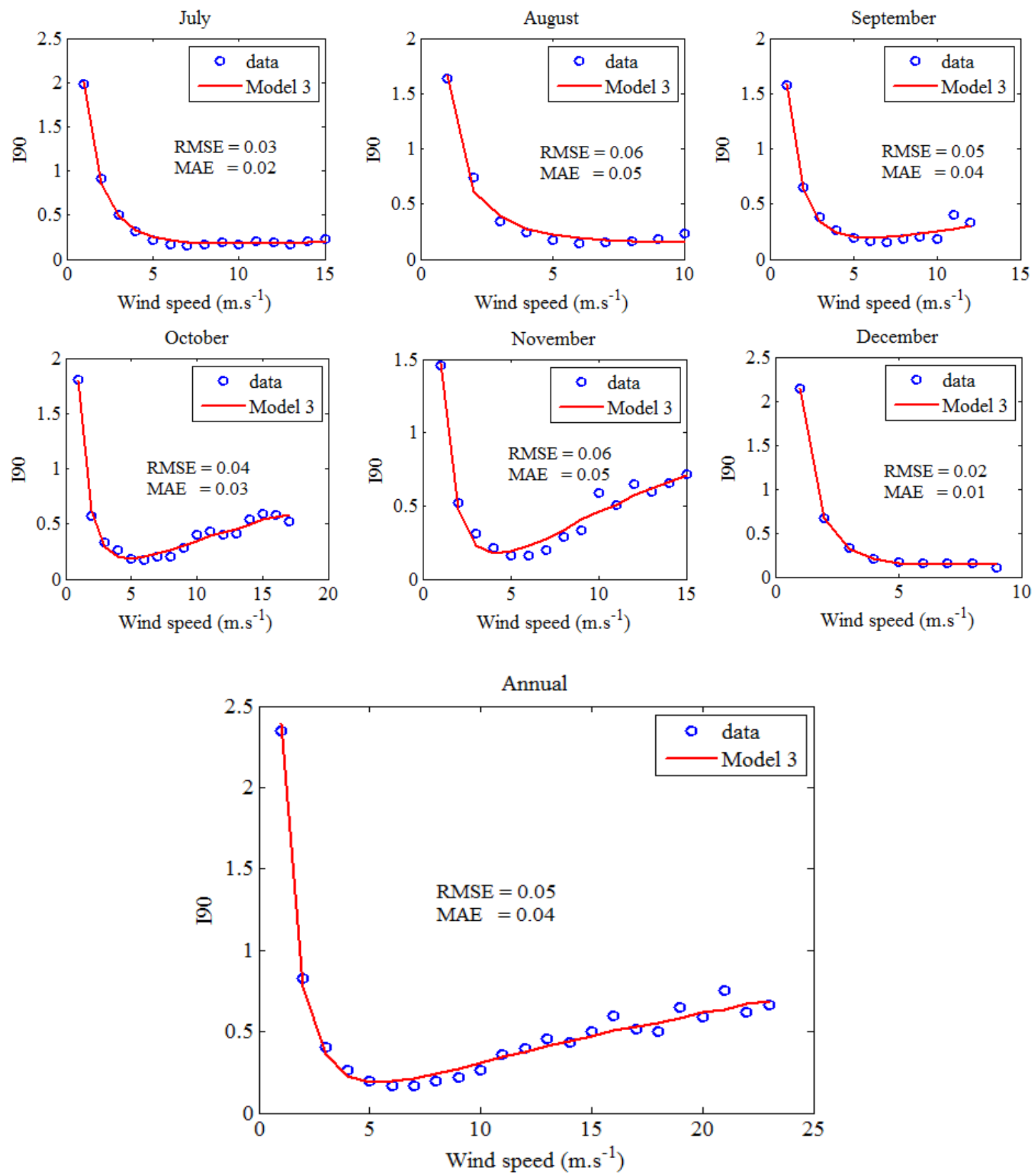

Fig. 10 Evaluation of the proposed model 3 with turbulence intensity data (2011-2014) (Cont..)

The model 3, which is a function of roughness and wind speed, better reproduces the different sequences of wind turbulence intensity whatever the time of year. The low values of the error estimators (MAE, RMSE) are obtained with this model. They vary from $(0.01 ; 0.02)$ observed in December to $(0.06 ; 0.08)$ observed in March. During the annual cycle, the model performance are also better. This model is more suitable for the site of Cotonou site (PAC).
It is therefore indicated for the sites where the wind turbulence intensity is a decreasing function of the wind speed for low and moderate winds and an increasing function when the winds are strong. The calibration constants included in model 3 and obtained after simulation are presented in Table 6 at monthly and annual scale. On the Figs. 11 and 12, the simulations of the proposed models 4 and 5 are presented. 
Table 6.

The calibration constant values of turbulence intensity model 3 .

\begin{tabular}{cccccc}
\hline & \multicolumn{5}{c}{ Model 3 } \\
\hline Period & $\mathbf{a}_{\mathbf{2}}$ & $\mathbf{b}_{\mathbf{2}}$ & $\boldsymbol{\tau}_{\mathbf{2}}$ & $\mathbf{d}$ & $\boldsymbol{\mu}_{2}$ \\
\hline January & -0.89 & 2.84 & -0.29 & -0.45 & 0.48 \\
February & -2.42 & 28.64 & -0.62 & -4.35 & 0.16 \\
March & 86.7 & 19.98 & -0.44 & -4.28 & 0.16 \\
April & -1.02 & 0.63 & -0.13 & 0.48 & 0.75 \\
May & -9.23 & 14.44 & -0.54 & -2.37 & 0.25 \\
June & -0.045 & 7.64 & -0.35 & -1.76 & 0.30 \\
July & -0.361 & 1.24 & -0.15 & 0.15 & 0.48 \\
August & 0.24 & 2.63 & -0.15 & -1.09 & 0.30 \\
September & -1.97 & 7.81 & -0.29 & -2.34 & 0.25 \\
October & 0.88 & 4.66 & -0.29 & -1.18 & 0.38 \\
November & -2.91 & 9.42 & -0.38 & -2.23 & 0.28 \\
December & 0.38 & 0.446 & -0.14 & 0.74 & 0.88 \\
Annual & -2.05 & 3.24 & -0.30 & -0.55 & 0.47 \\
\hline
\end{tabular}
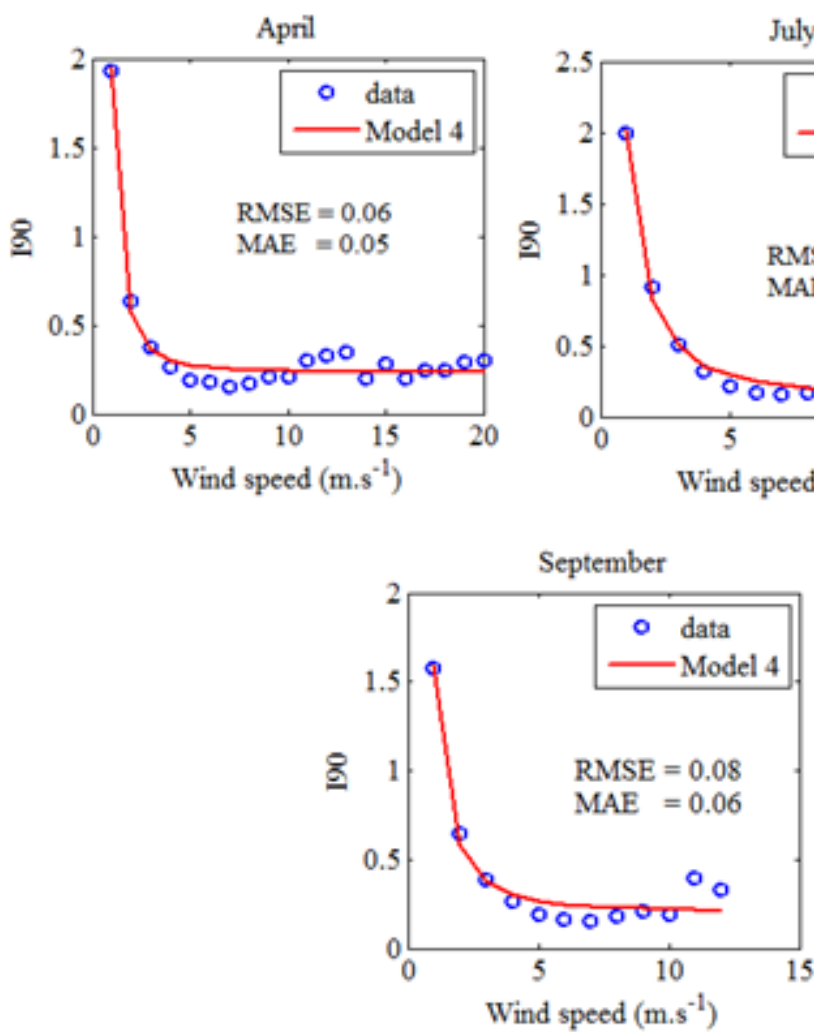
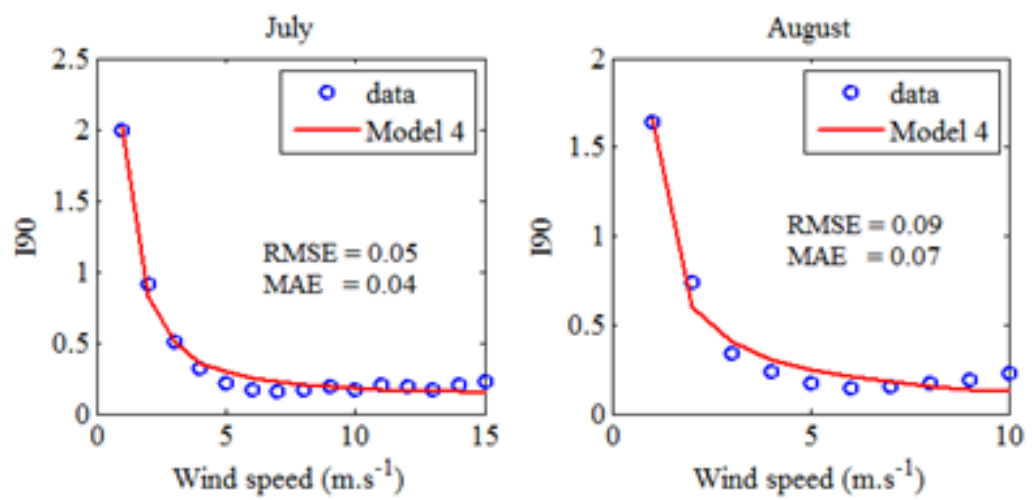

December

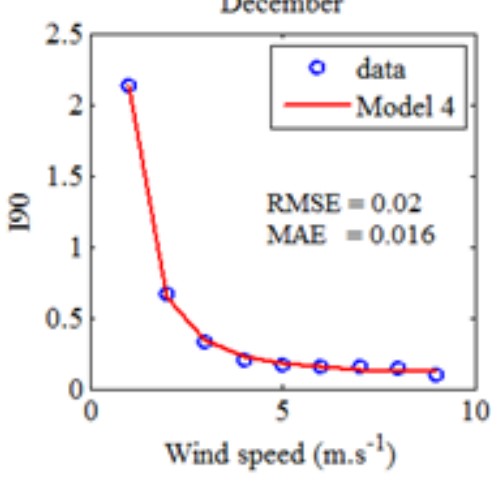

Fig. 11 Evaluation of the proposed model 4 with turbulence intensity data in stable atmosphere conditions (2011-2014). 

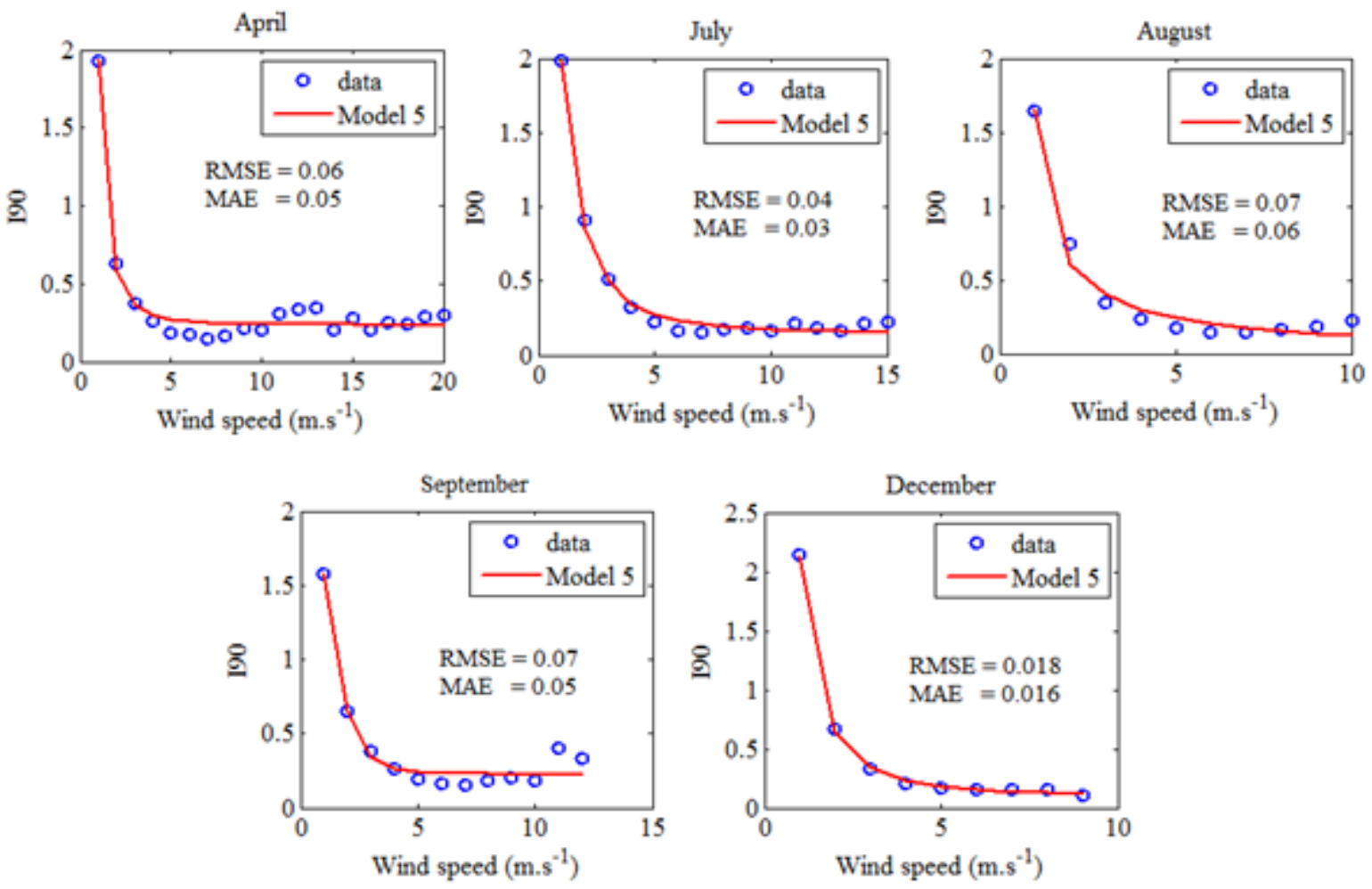

Fig. 12 Evaluation of the proposed model 5 with turbulence intensity data (2011-2014).

The analysis of the Figs. 11 and 12 shows that during the months of April, July, August, September and December, models 4 and 5 give a good fit with the data with less error for model 5 . The values of the MAE and RMSE range from (0.018; 0.016) obtained in December to $(0.09$; 0.07) in August. As for the other months, the models do not reproduce all the sequences of the turbulence intensity distribution. Like the models 1 and 2 , models 4 and 5 would be well suitable for sites where the intensity of turbulence decreases with wind speed.

In short, only model 3 among the 5 proposed models is more adapted to the study site whatever the time of the year and the wind speed range. To test its reliability according to the atmosphere stability conditions, this model was then simulated during the unstable and stable period of the atmosphere (Figs. 13 and 14).

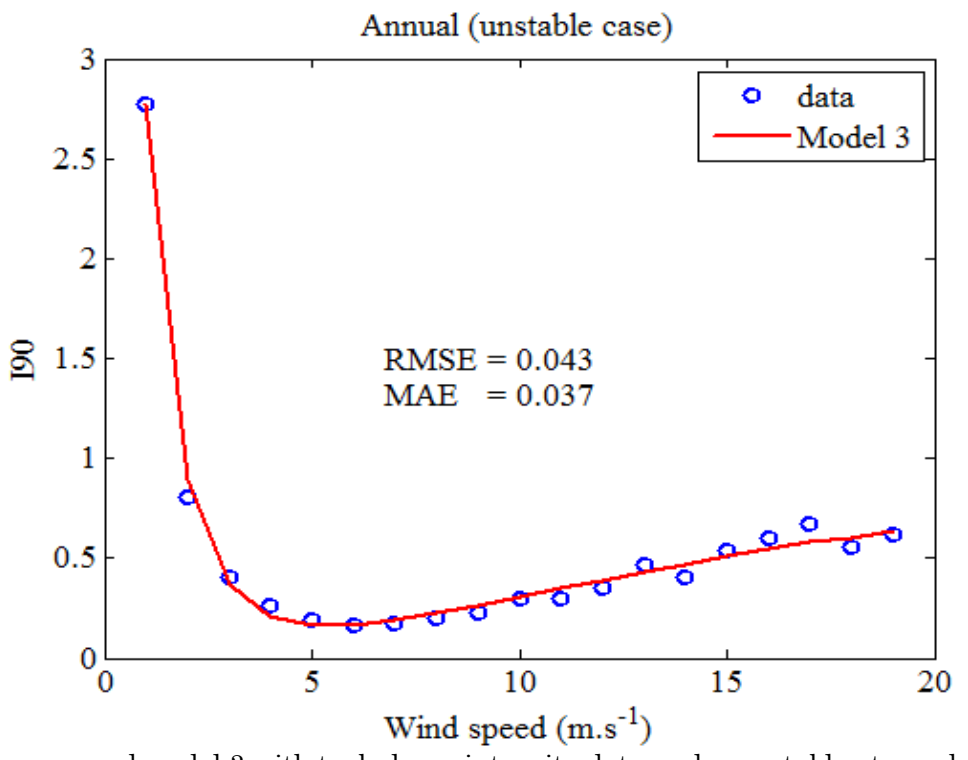

Fig. 13 Evaluation of the proposed model 3 with turbulence intensity data under unstable atmosphere conditions. (2011-2014). 

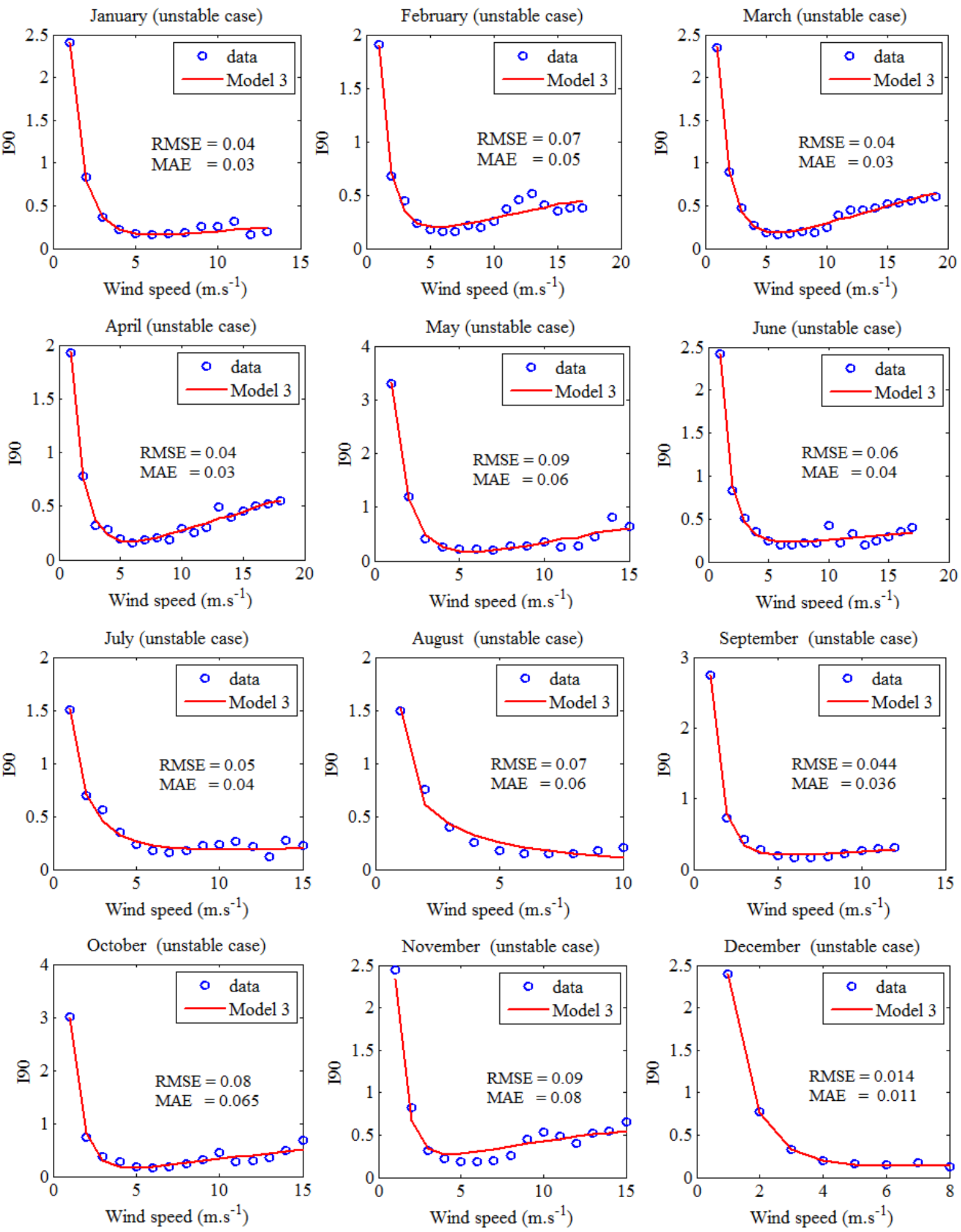

Fig. 13 Evaluation of the proposed model 3 with turbulence intensity data under unstable atmosphere conditions. (2011-2014). (Cont..) 

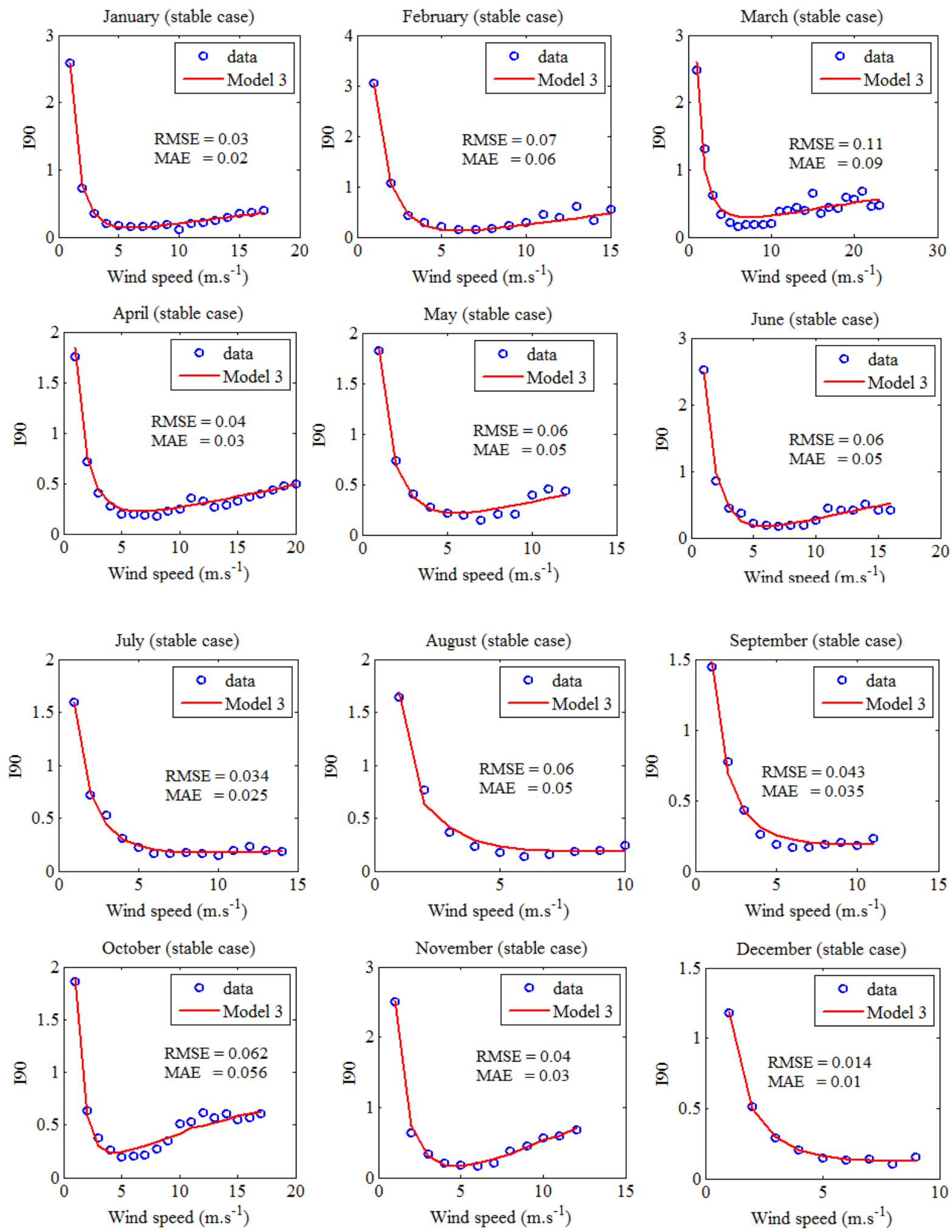

Fig. 14 Evaluation of the proposed model 3 with turbulence intensity data under stable atmosphere conditions. (2011-2014). 


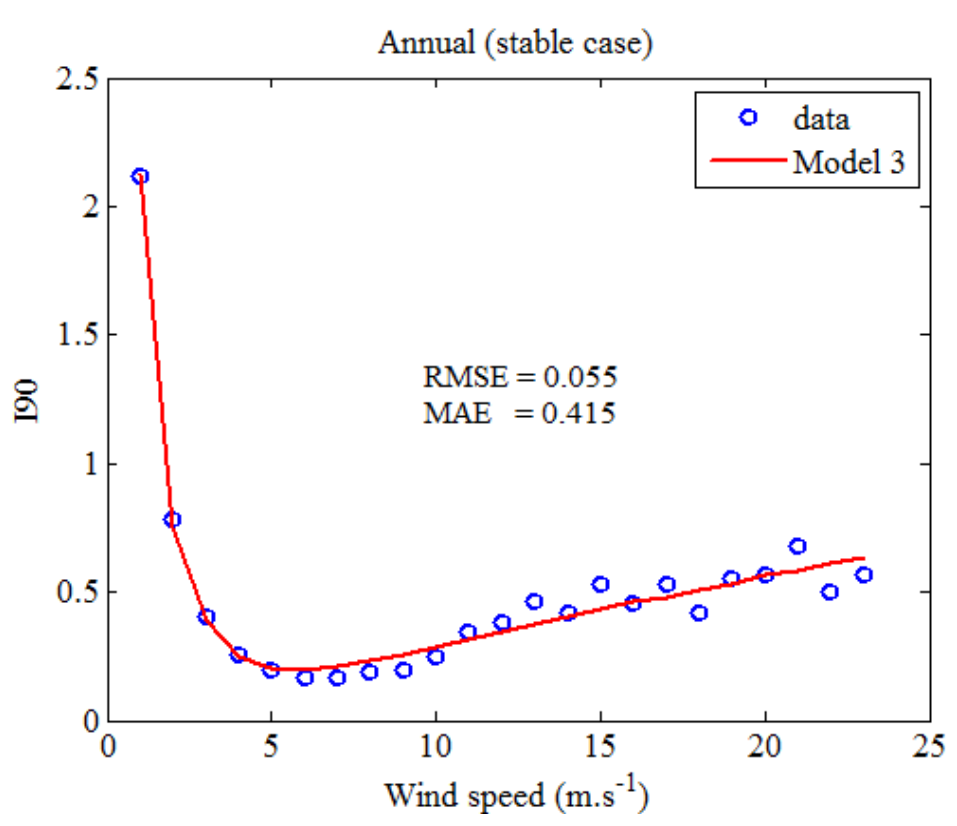

Fig. 14 Evaluation of the proposed model 3 with turbulence intensity data under stable atmosphere conditions. (2011-2014) (Cont...)

The model 3 shows a good performance whatever the conditions of stability of the atmosphere. When the atmosphere is stable, wind turbulence estimation errors vary from $(0.01 ; 0.014)$ in December to $(0.09 ; 0.11)$ in March. For an unstable atmosphere it is between $(0.01$; $0.014)$ obtained in December and $(0.08 ; 0.09)$ observed in November. For the annual cycle, this model presents a good fit during the unstable and stable atmospheric conditions. Low estimation errors are observed and respectively estimated at $(0.037 ; 0.043),(0.055 ; 0.415)$. In view of the errors obtained, we noticed that this model is more adapted in the convective period than when the atmosphere is stable. In considering the performances observed by the different proposed models, we noticed that the ground roughness and the wind shear coefficient (expressed only according to the wind speed) are the parameters of atmospheric dynamics that would most influence the intensity of wind turbulence at $10 \mathrm{~m}$ on our site.

\subsubsection{Comparative study of wind turbulence intensity estimation models}

Fig. 15 shows a comparison between the models of wind turbulence intensity estimation taken in the literature with the best proposed model in this study and the data (case of atmosphere without condition). The models taken in the literature were first calibrated with the data by numerical simulation from the fminsearch function. After analyzing Figure 15 and Table 8 , we noticed that throughout the year, only the proposed model 3 gives better results compared to the other models. The lowest values of RMSE are obtained for this model and vary from
0.0165 to 0.0857 . The models taken from the literature and calibrated to our site data underestimated or overestimated the wind turbulence intensity on the range of the observed wind speeds. However, during the period of April, July, August, September and December, the model of Ren et al. (2018) gives a good fit with the data. The RMSE is estimated respectively at $(0.0617 ; 0.0532$, $0.0719 ; 0.0804 ; 0.0186)$. In July and August, the model of Cheung et al. (2016) also gives a good approximation of the wind turbulence intensity. The model estimation errors are evaluated respectively at $(0.0692 ; 0.0722)$. For annual data, the models taken from the literature underestimate or overestimate the data according to the range of wind speeds. Only the proposed model 3 gives thus a better estimate of the turbulence. The normal model of IEC turbulence has therefore shown its limits whatever the time of the year with high values of the error estimators. It is therefore not indicated for the design of wind turbines on our study site. In short, the results from the comparative study indicate that model 3 proposed in this study is more adapted than the existing models. For its application, only two parameters are necessary. The hypothesis formulated in this study that the average profile of wind shear can be expressed like a function of the wind shear coefficient is therefore verified. It can therefore reasonably represent the high, the average and low levels of turbulence observed at a site. This model can therefore be validly used after calibration on any site. It is therefore recommended for the design of wind turbine blades on our study site and other similar sites. The error estimators (RMSE) between the models and the data are evaluated and presented in Table 7. 

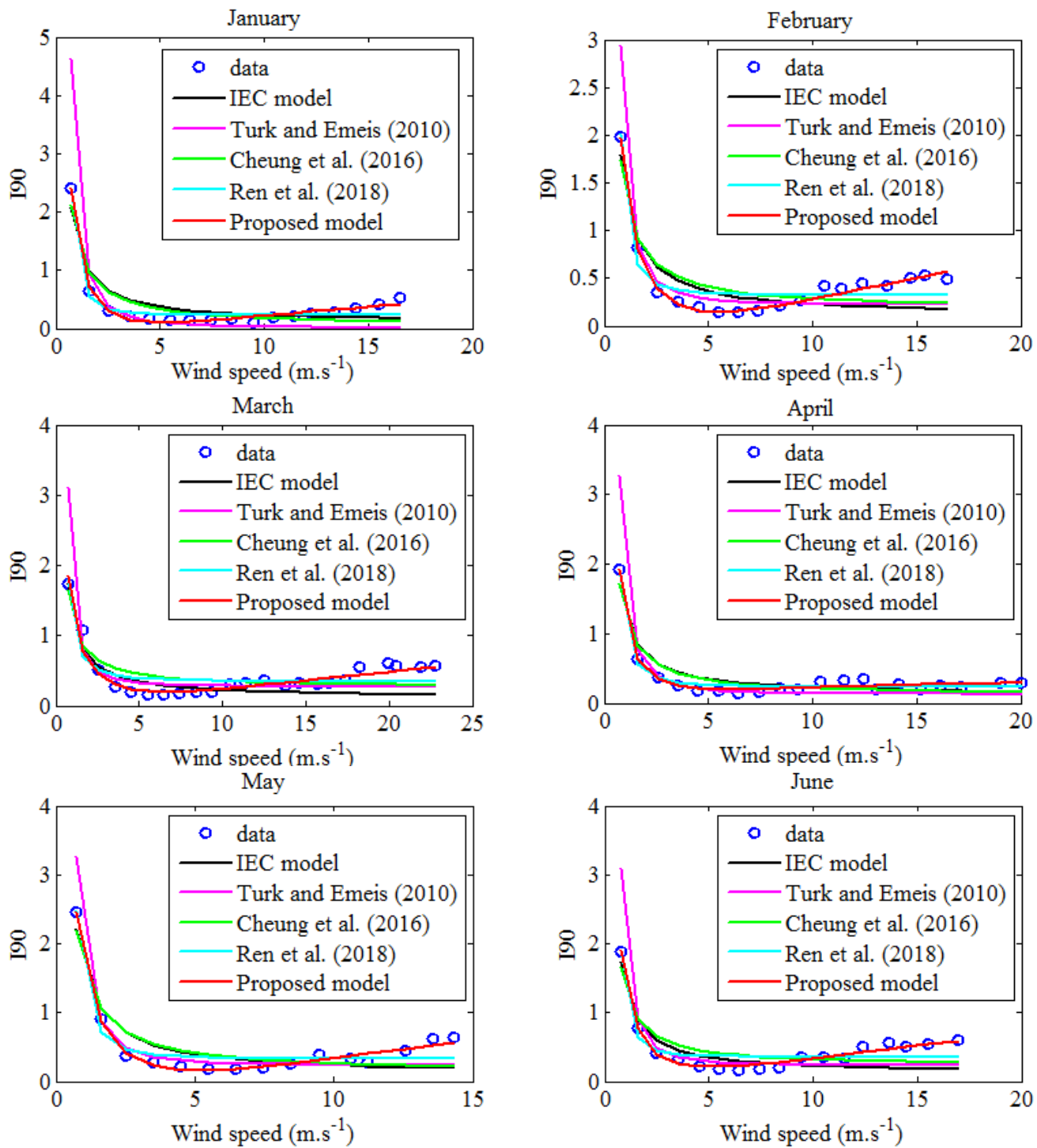

July
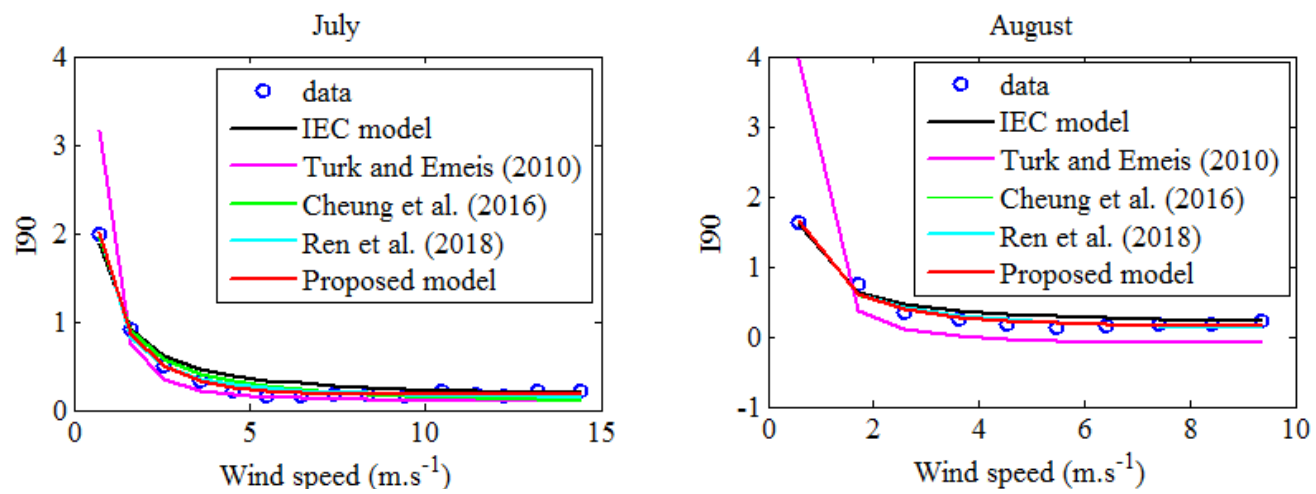

Fig. 15. Comparison of wind turbulence intensity models (2011-2014) 

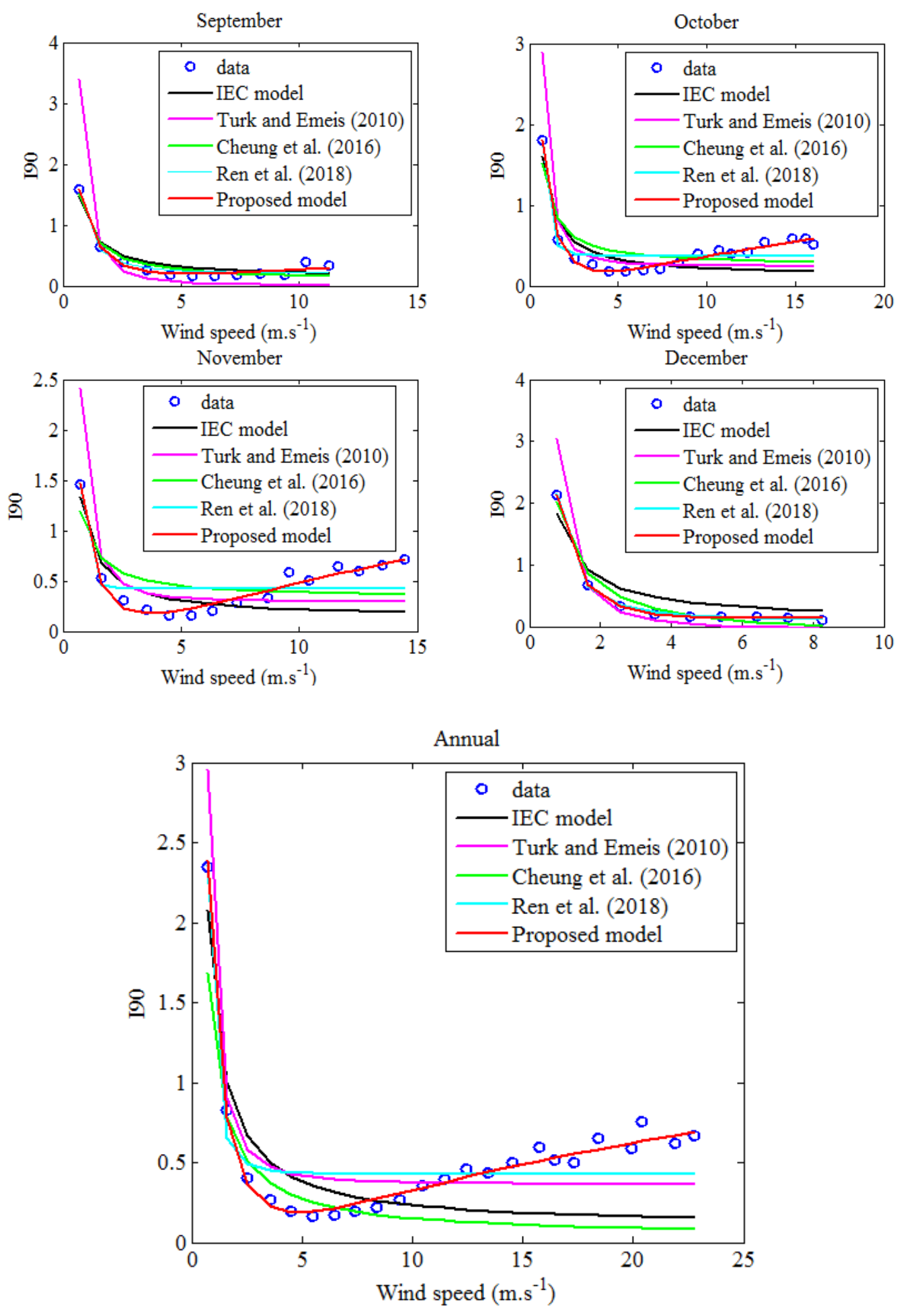

Fig. 15. Comparison of wind turbulence intensity models (2011-2014) (Cont..) 
Citation: Donnou, H.E.V., Akpo, A.B., Houngue, G.H. and Kounouhewa, B.B. (2020) Assessment of IEC Normal Turbulence Model and Modelling of the Wind Turbulence Intensity for Small Wind Turbine Design in Tropical Area: Case of the Coastal Region of Benin. Int. Journal of Renewable Energy Development, 9(2), 263-286, doi: 10.14710/ijred.263-286 $\mathrm{P}$ ag e $\mid 284$

Table 7

Root Mean Square Error (RMSE) between models and data at $10 \mathrm{~m}$ (2011-2014).

\begin{tabular}{rccccc}
\hline & $\begin{array}{c}\text { Best model } \\
\text { proposed } \\
\text { RMSE }\left(\mathrm{m} . \mathrm{s}^{-1}\right)\end{array}$ & IEC model & $\begin{array}{c}\text { Turk and Emeis } \\
(2010) \\
\text { RMSE }\left(\mathrm{m} . \mathrm{s}^{-1}\right)\end{array}$ & $\begin{array}{c}\text { Cheung et al. } \\
(2016) \\
\text { RMSE }\left(\mathrm{m} . \mathrm{s}^{-1}\right)\end{array}$ & Ren (2018) \\
\hline Jan & 0.0523 & 0.22 & 0.5839 & 0.2154 & 0.1119 \\
Feb & 0.0433 & 0.2141 & 0.2825 & 0.2079 & 0.1419 \\
Mar & 0.0857 & 0.2254 & 0.3319 & 0.1903 & 0.1724 \\
Apr & 0.0451 & 0.1286 & 0.3184 & 0.1283 & 0.0617 \\
May & 0.0564 & 0.2390 & 0.2699 & 0.2381 & 0.1583 \\
Jun & 0.0498 & 0.2202 & 0.3114 & 0.2024 & 0.1438 \\
Jul & 0.0296 & 0.10 & 0.3159 & 0.0692 & 0.0532 \\
Aug & 0.0593 & 0.1047 & 0.7745 & 0.0722 & 0.0719 \\
Sep & 0.0485 & 0.1117 & 0.5583 & 0.1037 & 0.0804 \\
Oct & 0.0415 & 0.2345 & 0.32 & 0.2128 & 0.1357 \\
Nov & 0.0594 & 0.287 & 0.34 & 0.244 & 0.1890 \\
Dec & 0.0165 & 0.2314 & 0.32 & 0.1114 & 0.0186 \\
Ann & 0.0488 & 0.3132 & 0.23 & 0.2627 & 0.1789 \\
\hline
\end{tabular}

\subsection{New design class of wind turbines}

The wind turbine class is defined by three parameters: the average wind speed at the hub height of the wind turbine, the extreme wind on a period of 50 years and the turbulence (IEC61400-2- (2013)). Three classes of turbulence are defined in a form similar to the normal turbulence model of IEC 61400-3. Model 3 can be rewritten as follows:

$$
I=\left(H_{0}+\tau_{2} l_{S L}[\ln (U)-d] U^{-\mu_{2}}\right) I_{r e f}
$$

with

$$
H_{0}=a_{2} z_{0}+b_{2}
$$

The values of $V_{\text {ref }}$ have been obtained from the expression of constant extreme wind model. This model is contained in the IEC61400-1 standard. Table 8 presents the new wind turbine design class defines for the coast of Benin in Cotonou. Like the Cotonou site, the new basic parameters for SWT can be determined from the model 3 on the sites which present the same characteristics with Cotonou.

Table 8.

New basic parameters for SWT turbines classes on the site of Cotonou at $10 \mathrm{~m}$.

\begin{tabular}{cccccccc}
\hline Class & $\mathrm{I}_{\text {ref }}$ & $\mathrm{V}_{\text {ref }}(\mathrm{m} / \mathrm{s})$ & $\overline{\mathrm{V}}(\mathrm{m} / \mathrm{s})$ & $\mathrm{H}_{0}$ & $\tau$ & $\mathrm{D}$ & $\mu$ \\
$\mathrm{A}$ & 0.50 & 32 & 4.53 & 6.50 & -0.60 & -0.55 & 0.47 \\
$\mathrm{~B}$ & 0.54 & 25 & 4.52 & 6.70 & -0.66 & -0.46 & 0.49 \\
$\mathrm{C}$ & 0.53 & 32 & 4.54 & 7.78 & -0.54 & -0.94 & 0.38 \\
\hline
\end{tabular}

A : (Atmosphere without condition), B (Atmosphere unstable), C (Atmosphere stable)

\section{Conclusions}

In this study, wind data recorded at $10 \mathrm{~m}$ above the ground on the site of Cotonou Port Authority were used to model the wind turbulence intensity from the turbulent kinetic energy transport equation followed by a numerical simulation based on the fminsearch function. The best model proposed was then compared to the models taken in the bibliography. The limitations of the IEC normal turbulence model and the existing ones have been clarified. Finally a new wind turbine design class has been proposed for our site. At the outcome of this study, the following conclusions are drawn:

- The turbulence intensity decreases to reach a threshold value ranging from 7 to $13 \mathrm{~m} / \mathrm{s}$ and increases beyond these values depending on the time of year. This is contrary to the decreasing assumptions of $\mathrm{I}_{\mathrm{U}}$ on the entirety wind speed range formulated in the normal turbulence model.

- Five models for estimating of the wind turbulence intensity were proposed. Alone the model 3, which is a function of roughness and the wind shear coefficient (expressed only according to the wind speed), gives a better performance whatever the time of year. The error estimators range from $(0.01$; $0.02)$ in December to $(0.06 ; 0.08)$ observed in March. The combined action of these two parameters (roughness and wind shear) in the turbulence intensity model is therefore important to represent all the sequences of the $\mathrm{I}_{\mathrm{U}}$ distribution.

- The hypothesis formulated in this study that the average profile of wind shear can be expressed like a function of the wind shear coefficient is therefore verified. 
- A comparative study between the existing models in the literature and model 3 showed that only the proposed model gives a good fit with the data. It is more reliable and is therefore recommended for estimating fatigue loads when designing wind turbines.

- Finally a new wind turbine design class has been designed for the site of Cotonou.

This study contributes to a better understanding of the turbulence intensity distribution on our study site. The consideration of these variations is important for the future design of wind turbines, the optimization of wind energy production and the study of aerodynamic loads on wind turbine blades on our study site. An improvement of the parametrization of the models $1,2,4$ and 5 could be conclusive whatever the site considered, the period of the year and will be the object of our next studies.

\section{Acknowledgements}

The authors of this paper sincerely thank the project Millennium Challenge Account compact I (MCA) for having made the wind data available to them, which were used to carry out this research work.

\section{References}

Akpo, A. B., Damada, J. C. T., Donnou, H. E. V., Kounouhewa, B. and Awanou C. N. (2015) Estimation de la production énergétique d'un aérogénérateur sur un site isolé dans la région côtière du Bénin. Revue des Energies Renouvelables, 18(3), 457-468.

Amar, F. B., Elamouri M, and Dhifaoui R. (2008) Energy assessment of the first wind farm section of Sidi Daoud, Tunisia. Renewable Energy, 33(10), 2311-2321.

Awanou, C. N., Degbey, J. M and Ahlonsou, E. (1991) Estimation of the mean wind energy avaible in Benin (ex Dahomey). Renew. Energy, 1 5/6 40, 845-853.

Barthelmie, R. J., Frandsen, S. T and Nielsen, M. N. (2007) Modelling and Measurements of Power Losses and Turbulence Intensity in Wind Turbine Wakes at Middelgrunden Offshore Wind Farm. Wind Energ, 10: 517528.

Businger, J. A., Wyngaard, J. C., Izumi, Y. and Bradley, E. F. (1971) Flux-profile relationships in the atmospheric surface layer. J Atmos Sci, 28, 181-189.

Carpman, N. (2011) Turbulence intensity in complex environments and its influence on small wind turbines. M.Sc. Dissertation. Department of Earth Sciences, Uppsala University

Chai, T., and Draxler, R. R., (2014) Root mean square error (RMSE) or mean absolute error (MAE)?-arguments against avoiding RMSE in the literature. Geoscientific Model Development, 7(3); 1247-1250.

Cheung, L. C., Premasuthan, S., Davoust, S., von Terzi D. (2016) A Simple Model for the Turbulence Intensity Distribution in Atmospheric Boundary Layers. Journal of Physics: Conference Series 753 032008.doi:10.1088/17426596/753/3/032008, 2016.

Corless, R. M. and Jeffrey, D. J. (2002) The Wright omega Function. Conference: Artificial Intelligence, Automated Reasoning, and Symbolic Computation," Joint International Conferences, AISC 2002 and Calculemus
2002, Marseille, France, July 1-5 Proceedings. J. Calmet et al (Eds.): AISC-Calculemus 2002, LNAI 2385, pp. 76-89 Springer-Verlag. (2002)

Darbieu, C., Lohou, F., Lothon, M., Vilà-Guerau de Arellano, J., Couvreux, F., Durand, P., Pino, D., Patton, E. G., Nilsson, E., Blay-Carreras, E. and Gioli, B. (2014) Turbulence vertical structure of the boundary layer during the afternoon transition. Atmos. Chem. Phys. Discuss, 14, 32491-32533.

Dimitrov, N., Natarajan, A. and Kelly M. (2015) Model of wind shear conditional on turbulence and its impact on wind turbine loads. Wind Energ 2015; 18, 1917-1931.

Dimitrov, N., Natarajan, A. and Mann, J. (2017) Effects of normal and extreme turbulence spectral parameters on wind turbine loads. Renewable Energy, 101, 1180- 1193.

Donnou, H. E. V., Akpo, A. B., Djossou, J., Kounouhewa, B. B. (2019c) Wind turbulence intensity characteristics at $10 \mathrm{~m}$ above ground along the Cotonou coast, Benin. International journal of sustainable and green energy, 8(4), 65-80.

Donnou, H. E. V., Akpo, A. B., Kouchadé, A. C., Kounouhewa, B. B., Hounguè, G. H. Nonfodji, G. F. and J. Djossou. (2019a) Vertical profile of wind diurnal cycle in the surface boundary layer over the coast of Cotonou, Benin, under a convective atmosphere. Advances in Meteorology, 2019, 118.

Dyer, A. J. (1974) A review of flux-profile relationships. Boundary-Layer Meteorol, 7, 363-372.

Evans, S. P., Anup, K. C., Bradney, D. R., Urmee, T. P. Whale, J. and P. D. Clausen P. D. (2017) The suitability of the IEC $61400-2$ wind model for small wind turbines operating in the built environment. Renew. Energy Environ. Sustain, 2(31), 1-7.

Finnigan J. J. (1994). Atmospheric boundary layer flows. Oxford University Press.

Gottschall, J. and Peinke, J. (2008) How to improve the estimation of power curves for wind turbines. Environmental Research Letters, 3(1), 15005-15007.

Gryning, S. E., Batchvarova, E., Brümmer, B., Jørgensen, H. and Larsen, S. (2007) On the extension of the wind profile over homogeneous terrain beyond the surface layer. BoundaryLayer Meteorol, 124, 251-268.

Gualtieri, G. (2015) Turbulence intensity as a predictor of extrapolated wind resource to the turbine hub height. Renewable Energy, 78, 68-81.

Hedevang, E. (2014) Wind turbine power curves incorporating turbulence intensity. Wind Energy, 17(2), 173-195.

Högström, U. (1988) Non-dimensional wind and temperature profiles in the atmospheric surface layer: a re-evaluation. Boundary-Layer Meteorol, 42, 55-78.

Houekpoheha, M. A., Kounouhewa, B., Tokpohozin, B. N., and Awanou C. N. (2014) Estimation de la puissance énergétique éolienne à partir de la distribution de weibull sur la côte béninoise de Cotonou dans le golfe de guinée. Revue des Energies Renouvelables, 17, 489-495.

Houngninou, B. E., Allé, C. S. U., Guédjé, K. F., and Kougbéagbédè, H. (2017) Changes in near-surface wind speed in the south of Benin from 1961 to 2016. Int. J. Adv. Res, 5(11), 1223-1232.

Hounguè, G. H., Kounouhewa, B. B., Tokpohozin, B. N., Houekpoheha, M. A., Madogni, V. I. and Almar, R. (2018) Wave Energy Impact on Benin's Coastline Dynamics, Gulf of Guinea. Current Journal of Applied Science and Technology, 30(4), 1-12.

IEC 61400.2-2013. Wind Turbines Part 2. Design Requirements for Small Wind Turbines Australia Standard: Australia, 2013.

Ishihara, T., Yamaguchi, A., Oikawa, S., Sarwar, M. W. (2012) A Study of the Normal Turbulence Model in IEC61400-1. Wind Energy, 96, 142-147. 
Kaiser, K., Langreder, W., Hohlen, H. and Højstrup J. (2004) Turbulence Correction for Power Curves. Wind Energy, 159-162.

Kamada, Y., Maeda, T., Murata, J., Toki, T. and Tobuchi A. (2011) Effects of Turbulence Intensity on Dynamic Characteristics of Wind Turbine Airfoil. Journal of Fluid Science and Technology, 6(3), 333-341.

Kim, S. H., Shin, H. K., Joo, Y. C. and Kim K. H. (2015) A study of the wake effects on the wind characteristics and fatigue loads for the turbines in a wind farm. Renewable Energy, $74,536-543$

Lagarias, J. C., Reeds, J. A., Wright, M. H., and Wright, P. E. (1998) Convergence Properties of the Nelder-Mead Simplex Method in Low Dimensions. SIAM Journal of Optimization, 9(1), 112-147.

Leu, T. S., Yo, J. M., Tsai, Y. T., Miau, J. J. and Wang, T. C. (2014) Assessment of IEC 61400-1 normal turbulence model for wind conditions in Taiwan West Coast areas," 5th International Symposium on Physics of Fluids (ISPF5) International Journal of Modern Physics: Conference Series 34 doi: $10.1142 /$ S2010194514603822.

Lopez-Villalobos, C. A., Hernandez-Cruz, O. R., Jaramillo, O. A., Mendoza J. L. (2018) Wind Turbulence Intensity at La Ventosa, Mexico: A Comparative Study with the IEC61400 Standards. Energies, 11(11), 1-19

Madougou, S. (2010) Etude du potentiel éolien du jet nocturne dans la zone sahélienne à partir des observations de radars profilers de vent. Thèse de Doctorat Université de Toulouse, France.

Marino, E., Giusti, A. and Manuel, L. (2017) Offshore wind turbine fatigue loads: The influence of alternative wave modeling for different turbulent and mean winds. Renewable Energy, 102, 157-169.

Mirhosseini, M., Sharifi, F. and Sedaghat, A. (2011) Assessing the wind energy potential locations in province of Semnan in Iran. Renew Sustain Energy Rev, 15: 449-59.

Nelder, J. A. and Mead, R. A. (1965) simplex method for function minimization. Computer Journal, 7, 308-313.

Newman, J. F. and Klein, P. M. (2014) The impacts of atmospheric stability on the accuracy of wind speed extrapolation methods. Resources, 3(1), 81-105.

Panofsky, H. A. (1973) 'Tower micrometeorogy. In: Haugeb DA (ed) Workshop on micrometeorolgy, American Meteorology Society, 151-176.

Peña A, Floors R, Sathe A, Gryning, S. E. , R. Wagner, R., Courtney, M. S., Hahmann, X. G. L. A. N. and Hasager, C. B. (2015) Ten Years of Boundary-Layer and Wind-Power
Meteorology at Høvsøre. Denmark. Boundary-Layer Meteorol, 158(1), 1-26.

Peña, A., Gryning, S. E., Charlotte, B., and Hasager, (2008) Measurements and Modelling of the Wind Speed Profile in the Marine Atmospheric Boundary Layer. Boundary-Layer Meteorol, 129: 479-495.

Pope, S. B. Turbulent Flows. Cambridge University Press. 771 PP. HTTPS://DOI.ORG/10.1017/S0022112000212913, 2000.

Ren, G, Liu J, Wan, J., Li, F., Y. Guo, Y. and Yu D. (2018) The analysis of turbulence intensity based on wind speed data in onshore wind farms. Renewable Energy, doi: 10.1016/j.renene. 2018.02.080.

Richard, E. and Dolle, A. (2011) Data Report (MCA): Development of a metocean station at the port of 579 Cotonou: Supply, installation, operation and maintenance of an oceanographic monitoring: (lot5)," 580 pp8-atm-145c, 65p.

Rosen, A. and Sheinman, Y. (1994) The average output power of a wind turbine in a turbulent wind. Journal of Wind Engineering \& Industrial Aerodynamics, 51(3), 287- 302.

Siddiqui, M. S., Rasheed, A., Kvamsdal, T., and Tabib M. (2015) Effect of Turbulence Intensity on the Performance of an Offshore Vertical Axis Wind Turbine. Energy Procedia, 80, 312-320.

Smedman-Högström, A. S., and Högström, U. A. (1983) A practical method for determining wind frequency distributions for the lowest $200 \mathrm{~m}$ from routine meteorological data. J Appl Meteor, 17, 942-954.

Sonia, W. and Lundquist, J. K. (2012) Assessing Atmospheric Stability and its Impacts on Rotor-Disk Wind Characteristics at an Onshore Wind Farm. Wind Energy, 15(4), 525-546.

Spera, D. A., and Richards, T. R. (1979) Modified power law equations for vertical wind profiles. In: Conference and workshop on wind energy characteristics and wind energy siting. Portland, OR, USA

Stival, L. J. L., Guetter, A. K. and de Andrade F. O. (2017) The impact of wind shear and turbulence intensity on wind turbine power performance. Espaço Energia, 27, 11-20.

Stull, R. B. (1988) An Introduction to Boundary Layer Meteorology. Kluwer Academic Publishers.

Turk, M. and Emeis, S. (2010) The dependence of offshore turbulence intensity on wind speed. J. Wind Eng. Ind. Aerodyn. 98, 466-471.

Wang, H., Barthelmie, R. J., Pryor, S. C., and Kim, H. G. (2013) A new turbulence model for offshore wind turbine standards. Wind Energy, 17(10), 1587-1604. 